\title{
Deformation of overburden soil induced by thrust fault slip
}

\author{
Ming-Lang Lin, Chun-Fu Chung, Fu-Shu Jeng * \\ Department of Civil Engineering, National Taiwan University, Taiwan
}

Received 15 December 2005; received in revised form 21 August 2006; accepted 23 August 2006

Available online 10 October 2006

\begin{abstract}
When the blind thrust fault slips due to earthquakes, overburden soil strata may deform and fail leading to a development of a coseismic fault zone. How overburden soil strata will deform or be faulted is an essential issue in the evaluation on the safety of ground/underground infrastructures located near the potential plastic zone. On the basis of previous work by Cole and Lade [Cole D.A., Lade, P.V., 1984. Influence zones in alluvium over dip-slip faults. Journal of Geotechnical Engineering 110, 599-615], this research further explores the processes of thrust faulting within overburden soil and examines the influences of corresponding factors or parameters under a range of boundary conditions using physical models and numerical analysis for both small-scale and full-scale configurations. Factors explored include uplifting rate, fault dip angle, dilation angle of plastic flow, Young's modulus, Poisson ratio, cohesive strength, frictional angle, scaling, as well as the location of ground loadings applied on ground surface.

The experimental results indicate that although one major fault slip surface can be developed, subsidiary faults may also form, which requires special attention when defining stain patterns. Young's modulus and the dilation angle are the most influential parameters in our models. A stiffer $E$ leads to early fault propagation and the occurrence of back-thrusts and causes more significant discrepancies in the deformation behaviors of models with different scales. A greater dilation angle of the overburden soil leads to a wider fault zone. The above-mentioned phenomena highlight that a careful consideration of the applicable Young's modulus and the dilation angle is essential in a proper simulation or prediction of the fault zone development. For small-scale, physical models used to simulate the fault development for a full-scale problem, the stiffness of model soil should be properly scaled down, which still requires further study.
\end{abstract}

(C) 2006 Elsevier B.V. All rights reserved.

Keywords: Thrust fault; Slip; Propagation; Overburden soil strata; Numerical analysis; Trishear model

\section{Introduction}

For underground structures, including tunnels for mass transportation, basements of buildings, pipelines etc., it is desirable that these structures should not be located near active faults. However, these structures sometimes have to be located inadvertently near active

\footnotetext{
* Corresponding author. Tel./fax: +8862 23645734

E-mail address: fsjeng@ntu.edu.tw (F.-S. Jeng).
}

faults (Bonilla, 1982; Konagai, 2001; Wang et al., 2001; Backblom and Munier, 2002; Konagai, 2003). In such cases, the response of these structures to ground deformation caused by earthquakes on nearby faults is of great concern, as shown in Fig. 1. For example, Taiwan was struck by an Mw 7.6 event, the Chichi Earthquake in 1999. Surface rupture in this earthquake occurred along $95 \mathrm{~km}$ of the Chelungpu Fault, with ground uplift ranging from 2 to $10 \mathrm{~m}$ (Chen et al., 2001; Lee et al., 2001). As during the earthquake, coseismic fault movement causes significant damage to buildings 


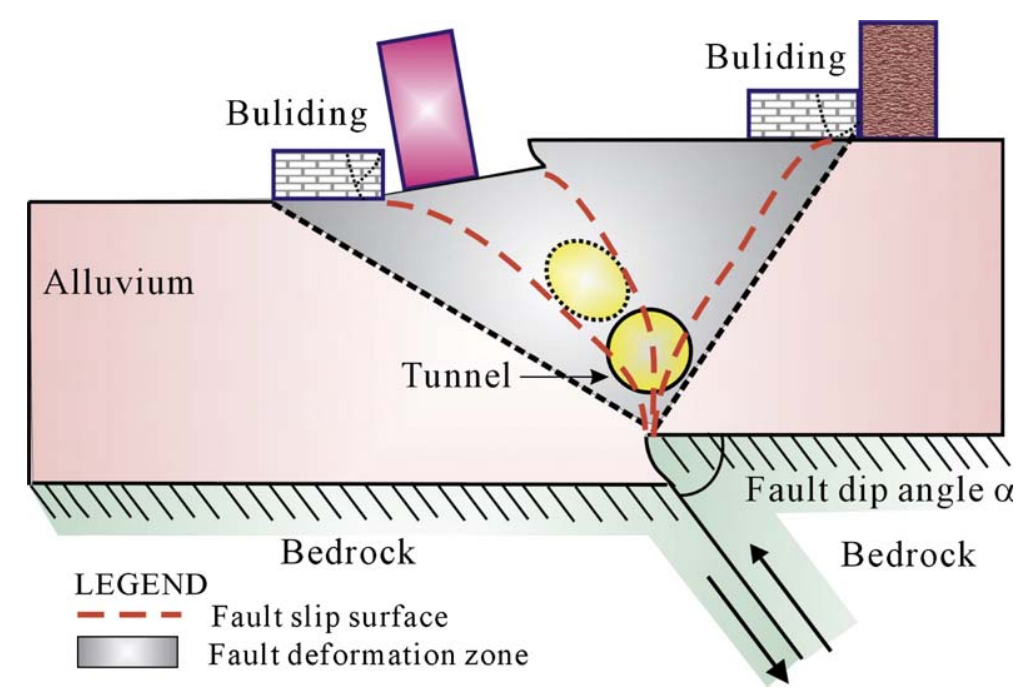

Fig. 1. Possible influence of thrust faulting on the overburden soil strata, modified after Cole and Lade (1984).

and underground structures near or within the deformation zone, especially when it occurs in metropolitan areas; see other examples in the USA (Landers, California, $\mathrm{Mw}=7.3,1992$ ), Turkey (Izmit, $\mathrm{Mw}=7.4$, 1999), Japan (Kobe, $\mathrm{Mw}=7.2,1995$ ) and other countries (Bray, 2001; Wang et al., 2001; Chung et al., 2005; Lin et al., 2005a; Konagai, 2001, 2003).

In an effort to define the deformation behavior of the Chelungpu Fault, trench excavations revealed that the fault slipped a few meters in several paleo-earthquakes with a return period of tens to a few hundred years (Chen et al., 2001; Lee et al., 2001, 2004; Chen et al., 2004; Ota et al., 2005). The dates of the paleo-earthquakes were estimated by sampling detrital charcoal from fluvial deposits exposed by trench excavation and by $\mathrm{C} 14$ radiocarbon dating to identify the time when the organic material was deposited. Meanwhile, the sequence of strata and the colluvium deposit were

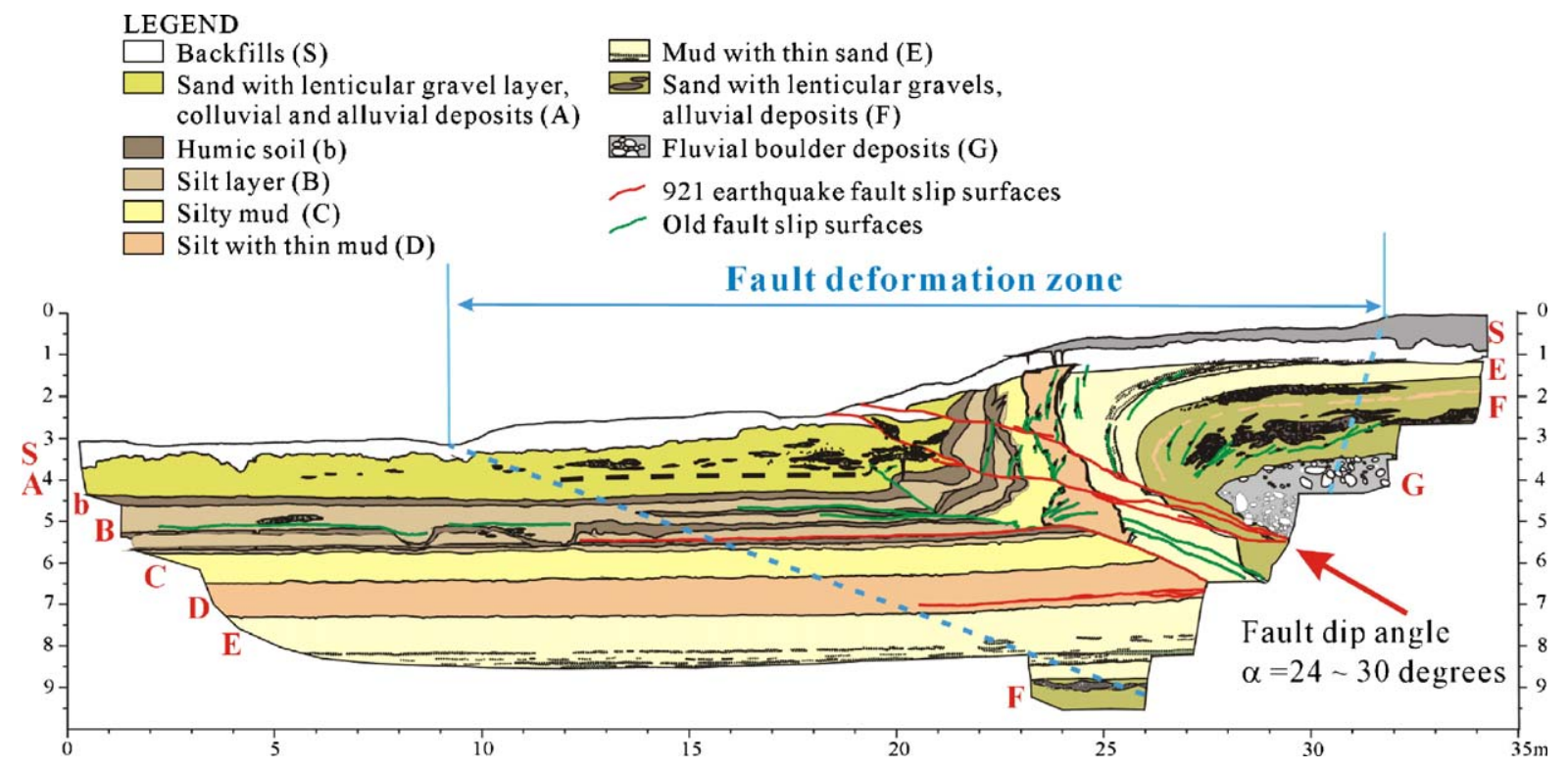

Fig. 2. Deformation of actual trust faulting (provided by Prof. W. S. Chen, 2005). The trench is located in Chushan, Nantou County, Taiwan. The deformation is characterized by several slip surfaces within a major fault zone and surface tension. The dip angle of the fault zone within the overburden soil strata gradually decreases from the bottom to the top surface. 
analyzed to identify how many paleo-earthquakes occurred. For the studied trench, as shown in Fig. 2, the strata containing the charcoals include sand with a lenticular gravel layer as well as colluvial and alluvial deposits (A); humic soil (b); slit layer (B); mud with thin sand $(\mathrm{E})$. Details can be found in Chen et al. (submitted for publication).

Furthermore, as shown in Fig. 2, separate sliding surfaces were developed within the major fault zone for each coseismic faulting event. For engineering applications, more understanding is needed to characterize deformation in and around fault slip surfaces activated by an earthquake (Cole and Lade, 1984; Lazarte and Bray, 1996).

Both physical sandbox experiment and numerical modeling of fault strain field and plastic deformation around the fault zone are important, as defined by previous works on thrust and strike-slip fault (Roth et al., 1982; Cole and Lade, 1984; Tani et al., 1994; Bray et al., 1994a; Lazarte and Bray, 1996; Chung et al., 2005; Lee and Hamada, 2005; Lin et al., 2005a). Scaling effects of experimental models with well-characterized natural examples of fault slip, as illuminated by the trench excavation, are also necessary components of these efforts (e.g. Lin et al., 2005b).

We also undertook sandbox experiments and numerical simulations, which enable a more detailed analysis of the stress and strain field to study the effect of deformation modulus, strain rate and other parameters (Duncan and Lefebvre, 1973; Roth et al., 1982; Bray et al., 1994b; Bray, 2001; Johansson and Konagai, 2004; Lin et al., 2005a,b).

Besides working to interpret the evolution of fault slip based on observation of fold and fault geometry in trench excavations or in sandbox experiments, we used trishear propagation fold theory to simulate the evolution of deformation during successive earthquakes (Erslev, 1991; Allmendinger, 1998; Zehnder and Allmendinger, 2000; Erickson et al., 2001; Johnson and Johnson, 2002; Cardozo et al., 2003; Chen et al., 2004). The trishear model is used to characterize the evolution of progressive strain and the upward propagation of the fault tip into overburden soil strata. In addition to the forward accrual of fault slip, an inverse analysis can also be conducted to restore older strain and locate the previous position of the fault tip (Champion et al., 2001).

Since the fault tip forms a singularity in the numerical analysis, these methods are not always the best choice for simulating the migration of fault tip into soil. Alternatively, it is difficult to define fault geometry prior to the most recent events where deformed strata of this age are not exposed in trench excavations. This highlights the merits of sandbox experiments, in which earlier fault geometry and slip can be constrained. As such, the sandbox experiments serve as good measures for validating the trishear model. Accordingly, this research also compared the sandbox experiments with the prediction of trishear model, and its overall validity.

Field observations have revealed that the development of fault traces can be affected by existing ground structures, or the so-called surcharges (Bray, 2001; Kelson et al., 2001; Dong et al., 2003; Anastasopoulos, 2005). We, therefore, considered the influence of surcharge in the numerical analysis.

Table 1

Summary of some the existing studies on soil deformation due to the fault movement

\begin{tabular}{|c|c|c|c|c|}
\hline Methodology & Fault type & $\begin{array}{l}\text { Fault dip } \\
\text { angle (deg.) }\end{array}$ & $\begin{array}{l}\text { Soil } \\
\text { type }\end{array}$ & $\begin{array}{l}\text { Soil } \\
\text { parameter }^{\mathrm{a}}\end{array}$ \\
\hline \multicolumn{5}{|l|}{ Numerical analysis } \\
\hline $\begin{array}{l}\text { Duncan and Lefebvre } \\
\text { (1973) }\end{array}$ & - & - & Sand & $\phi, v$ \\
\hline Roth et al. (1982) & $\begin{array}{l}\text { Normal } \\
\text { faults }\end{array}$ & 45 & Sand & $\phi, \psi, \varepsilon_{\mathrm{f}}$ \\
\hline Bray et al. (1994b) & $\begin{array}{l}\text { Thrust } \\
\text { faults }\end{array}$ & 45,90 & Clay & $\varepsilon_{\mathrm{f}}$ \\
\hline Bray (2001) & $\begin{array}{l}\text { Strike dip } \\
\text { faults }\end{array}$ & $10-85$ & Sand & $\phi, \varepsilon_{\mathrm{f}}$ \\
\hline $\begin{array}{l}\text { Johansson and } \\
\text { Konagai (2004) }\end{array}$ & $\begin{array}{l}\text { Thrust } \\
\text { faults }\end{array}$ & 30 & Sand & $\varepsilon_{\mathrm{f}}$ \\
\hline Lin et al. (2005a) & $\begin{array}{l}\text { Thrust } \\
\text { faults }\end{array}$ & $20-90$ & Sand & $\phi, \psi$ \\
\hline \multicolumn{5}{|l|}{ Model experiment } \\
\hline $\begin{array}{l}\text { Cole and Lade } \\
\text { (1984) }\end{array}$ & $\begin{array}{l}\text { Strike dip } \\
\text { faults }\end{array}$ & $0-180$ & Sand & $\psi$ \\
\hline Roth et al. (1982) & $\begin{array}{l}\text { Normal } \\
\text { faults }\end{array}$ & 45 & Sand & $\phi, \psi, \varepsilon_{\mathrm{f}}$ \\
\hline Bray et al. (1994b) & $\begin{array}{l}\text { Thrust } \\
\text { faults }\end{array}$ & 45,90 & Clay & $\varepsilon_{\mathrm{f}}$ \\
\hline $\begin{array}{l}\text { Lazarte and Bray } \\
\text { (1996) }\end{array}$ & $\begin{array}{l}\text { Strike slip } \\
\text { faults }\end{array}$ & - & Clay & $\varepsilon_{\mathrm{f}}$ \\
\hline Tani et al. (1994) & $\begin{array}{l}\text { Strike dip } \\
\text { faults }\end{array}$ & $15-180$ & Sand & $\phi, \varepsilon_{\mathrm{f}}$ \\
\hline $\begin{array}{l}\text { Lee and Hamada } \\
\text { (2005) }\end{array}$ & $\begin{array}{l}\text { Strike dip } \\
\text { faults }\end{array}$ & $30,45,60$ & Sand & $\phi, \psi, \varepsilon_{\mathrm{f}}$ \\
\hline Lin et al. (2005a) & $\begin{array}{l}\text { Thrust } \\
\text { faults }\end{array}$ & 50,60 & Sand & $\phi, \psi$ \\
\hline \multicolumn{5}{|l|}{ Field studies } \\
\hline Lade et al. (1984) & $\begin{array}{l}\text { Strike dip } \\
\text { faults }\end{array}$ & $0-180$ & Sand & $\psi$ \\
\hline \multirow[t]{2}{*}{ Bray et al. (1994a) } & $\begin{array}{l}\text { Strike dip } \\
\text { faults }\end{array}$ & - & Sand & - \\
\hline & $\begin{array}{l}\text { Strike slip } \\
\text { faults }\end{array}$ & - & Clay & - \\
\hline Bray (2001) & $\begin{array}{l}\text { Strike dip } \\
\text { faults }\end{array}$ & $10-85$ & Sand & $\phi, \varepsilon_{\mathrm{f}}$ \\
\hline
\end{tabular}

${ }^{\text {a }}$ Frictional angle: $\phi$; dilation angle: $\psi$; failure strain: $\varepsilon_{\mathrm{f}}$. 
Given the previous work on faulting in soils as listed in Table 1, our work further explores deformation of overburden soil induced by the thrust fault movement with emphasis on the following issues:

(1) Large deformation-where uplift is up to about $30 \%$ of the thickness of top soil; this is significantly greater than those $4 \%, 10 \%, 10 \%$ and $10 \%$ by Cole and Lade (1984), Bray et al. (1994b), Tani et al. (1994), and Lee and Hamada (2005) respectively.

(2) The sliding surface is not pre-set in both sandbox and numerical models so that a free development of the shear zone is allowed. By doing this, the possible influence of the pre-set geometry on the actual position of the fault tip and dip can be accordingly avoided.

(3) The development of several slip surfaces within the complex fault zone is also considered, as observed in the trench excavation and shown in Fig. 2;

(4) The influence of the slip rate of coseismic slip on deformation behavior is also considered;

(5) The influence of surcharge on fault and trishear fold development; and

(6) A comparison of the deformation predicted by the trishear model.

\section{Methodology}

The physical model study and the numerical analysis were adopted, for their ability to model large deformations and constrain fault zone geometry. The deformation of small-scale models, about 1:100, obtained from the physical model and the numerical model simulation is compared so that the adequacy of the numerical prediction can be justified as shown in Fig. 3 (Steps 1, 2 and 3). Based on the calibrated small-scale numerical model, a full-scale numerical model was then developed and used to simulate the deformation behavior of fullscale thrust fault deformation, which is of concern for construction of a mass-transportation tunnel near a thrust fault in Taipei, Taiwan (Fig. 3; Steps 4 to 6; Chung et al., 2005). Accordingly, the influence of factors including fault dip angle, strain rate, dilational angle, etc., can be revealed (Fig. 3, Step 7). Meanwhile, by comparing the deformations of small-scale and fullscale model, the scale effect can also accordingly be evaluated (Fig. 3, Step 8).

\subsection{Physical model-sandbox experiments}

A sandbox apparatus filled with layers of dyed sands was adopted to study the coseismic displacement and strain in overburden soil and the development of fault

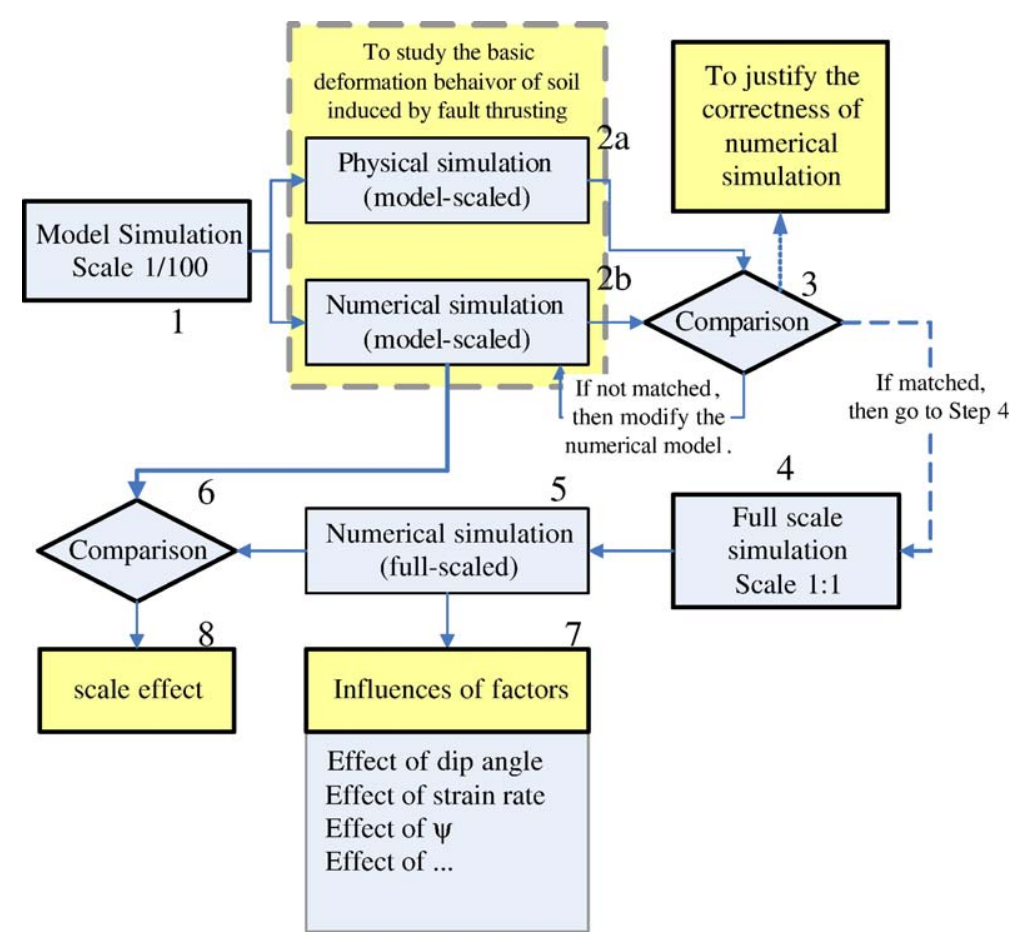

Fig. 3. Flowchart of this research. 
zone and sliding surfaces induced by thrust faulting, as illustrated in Fig. 4. The length, height and width of the sandbox are $100 \mathrm{~cm}, 60 \mathrm{~cm}$ and $20 \mathrm{~cm}$, respectively. The bottom of the box on the right side was free to move, simulating the displacement and uplift of a thrust fault, to a height of $20 \mathrm{~cm}$ with dip angles ranging from $15^{\circ}$ to $90^{\circ}$. A rubber sheet was placed between the base plate and the sand so that the leakage of sand from the bottom during faulting was prevented. The speed of hanging wall slip is controlled by a motor. In the test series, the thickness of sand simulating soil is $20 \mathrm{~cm}$ and the uplift is $6 \mathrm{~cm}$.

The model material, the sand, has properties summarized in Table 2. The Young's modulus of the studied sand varies with stress levels. Furthermore, both the Young's modulus and the Poison ratio depend on the relative density of sand. The relative density was selected to be $55 \%$, which is neither too loose to contract nor too dense to dilate when sand is sheared. The measured Poison ratio is 0.4 and is quite close to the incompressible state (Poison ratio $=0.5$ ). Sand is used in small-scale physical model tests in which the range of stress levels is relatively smaller than in full-scale model tests. The selected Young's modulus is based on the stress level encountered in the model test.

A frictional angle $\phi$ was measured as $30-34^{\circ}$ by direct shear and triaxial tests. The numerical analysis showed that a frictional angle at this range had very few influences. As such, the frictional angle of $30^{\circ}$ was selected for the numerical analysis.

The dilation angle of sand was measured as $9^{\circ}$. Since the dilation angle in full-scale model will vary from site
Table 2

Summary of the properties of the model material

\begin{tabular}{|c|c|c|c|c|c|}
\hline \multirow[t]{2}{*}{ Parameter } & \multirow[t]{2}{*}{ Experiment } & \multirow{2}{*}{$\begin{array}{l}\text { Model } \\
\text { scale }\end{array}$} & \multicolumn{2}{|c|}{ Full scale } & \multirow[t]{2}{*}{ Unit } \\
\hline & & & Case A & Case B & \\
\hline Young's modulus, $E$ & 1.29 & 1.29 & 1.29 & 5 & $\mathrm{MPa}$ \\
\hline Poisson ratio, $v$ & 0.4 & 0.4 & 0.4 & 0.4 & \\
\hline Cohesion, $c$ & 5 & 5 & 5 & 5 & $\mathrm{kPa}$ \\
\hline Frictional angle, $\phi$ & 30 & 30 & 30 & 30 & Degree \\
\hline Dilation angle, $\psi$ & - & 6,30 & 30 & 6,30 & Degree \\
\hline $\begin{array}{l}\text { Dry unit weight } \\
\text { of soil, } \gamma\end{array}$ & 15.7 & 15.7 & 15.7 & 20 & $\mathrm{kN} / \mathrm{m}^{3}$ \\
\hline $\begin{array}{l}\text { Stress ratio } \\
\text { at rest, } K_{0}\end{array}$ & & 0.5 & 0.5 & 0.5 & \\
\hline
\end{tabular}

to site, a parametric study for dilation angle ranging from $6^{\circ}$ to $30^{\circ}$ was accordingly conducted, as shown in Fig. 11. An associated flow rule, in which a dilation angle equals a friction angle, was conservatively selected for the base case since it would lead to a larger shear zone.

During the faulting process, photos were taken from the side of the box so that the deformation of strata could be recorded. The photos were then processed to correct distortion caused by parallax.

To facilitate observations of the deformation, a thin layer of dyed sand was layered within the undyed sand every $2 \mathrm{~cm}$ so that deformation could be measured more readily.

When the distortion of a dyed sand layer is visible in the photos, it indicates that faulting has reached this layer and the development of the broader fault zone can be defined, as shown in Fig. 5. A well-defined fault slip

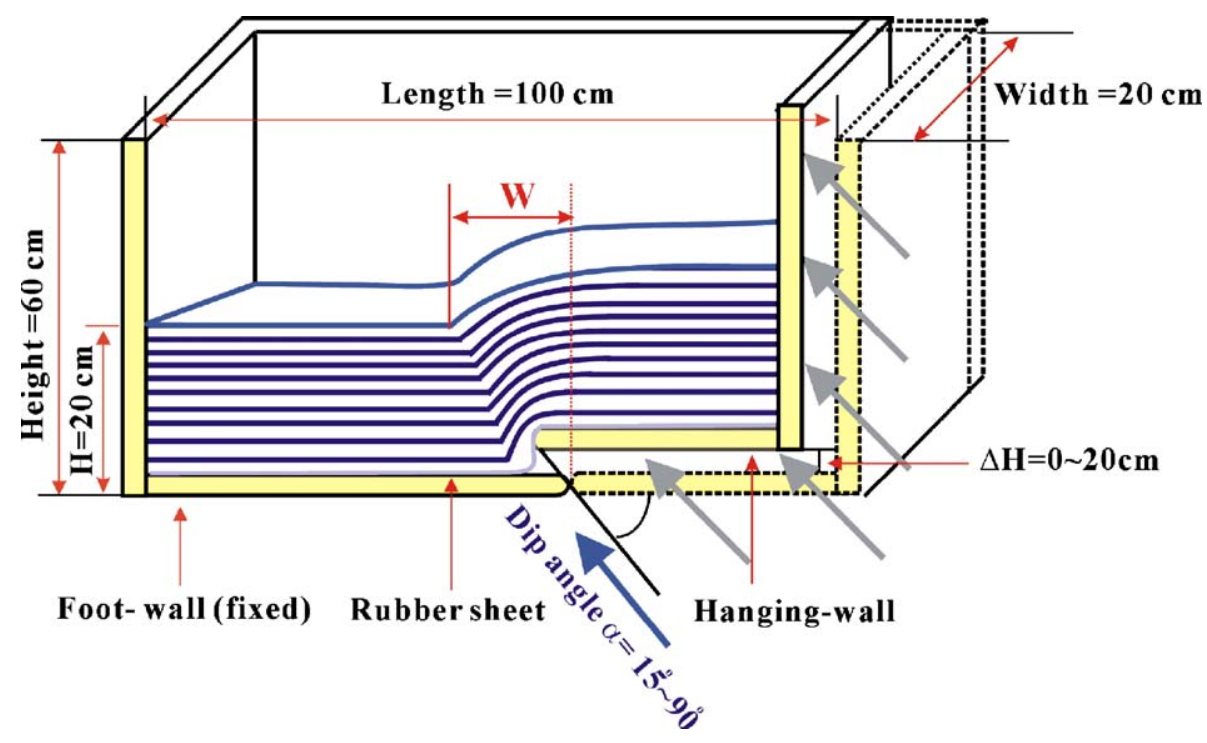

Fig. 4. Setup for the small-scale physical model. 


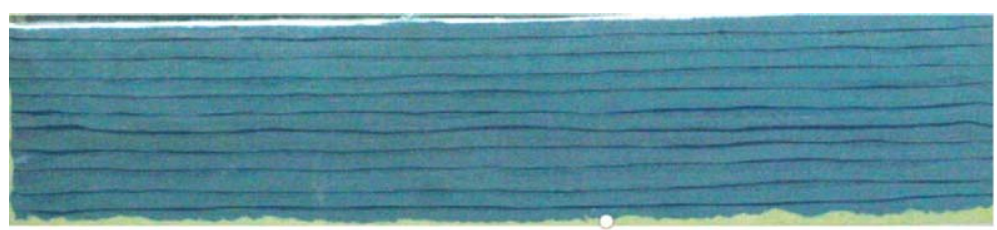

(a)

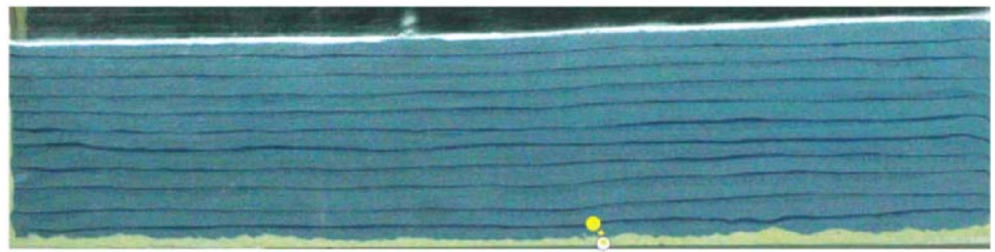

(b)

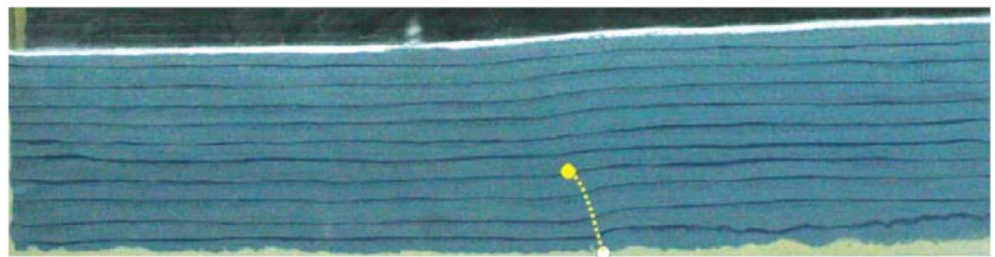

(c)

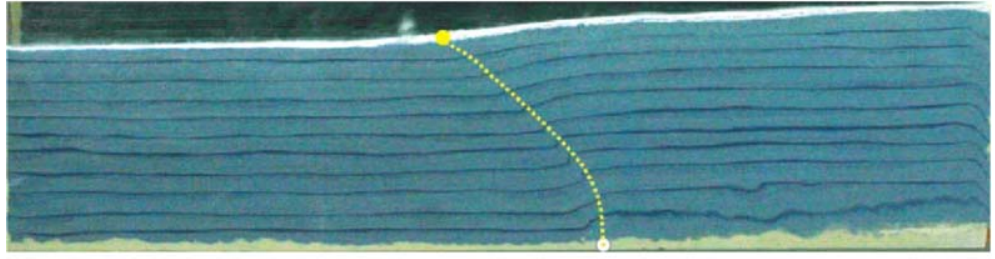

(d)

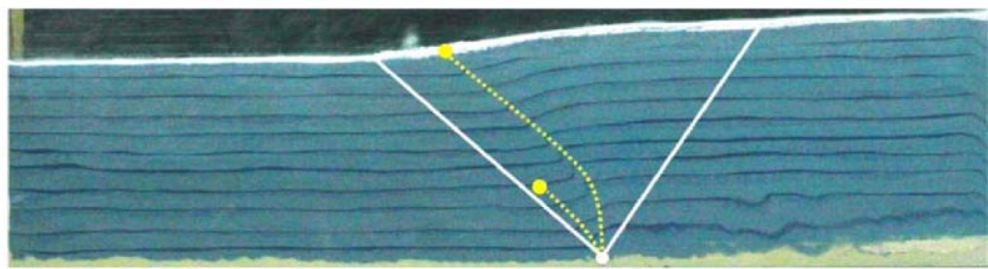

(e)

Fig. 5. Fault development subjected to increasing uplift, $\Delta H / H$. The highlighted light-colored points represent the fault tips. Dotted lines indicate the fault slip surfaces, and white lines indicate the deformation zone, position at stage. (a) $\Delta H / H=0.01$; (b) $\Delta H / H=0.05$; (c) $\Delta H / H=0.10$; (d) $\Delta H /$ $H=0.15$; (e) $\Delta H / H=0.20$.

surface or a fault zone, within the overburden soil strata can be identified in the latter stages of deformation (Fig. 5d and e).

\subsection{Numerical model}

A finite element method based software, ABAQUS (Hibbitt et al., 2004), was adopted for the numerical analysis. A two-dimensional model for simulating the thrust faulting is setup, as shown in Fig. 6. The right boundary is moved as shown in Fig. 6, to simulate the movement of the hanging wall. A roller condition was set for the left and the right boundaries of overburden soil. Friction occurred between sand and the bottom of sandbox. The same material properties of sand shown in Table 2 were also used for numerical modeling of deformations.

For the numerical analysis, the material inside the shear zone reaches a plastic state; therefore, contours of plastic strain serve as a good indicator for the boundary of the 


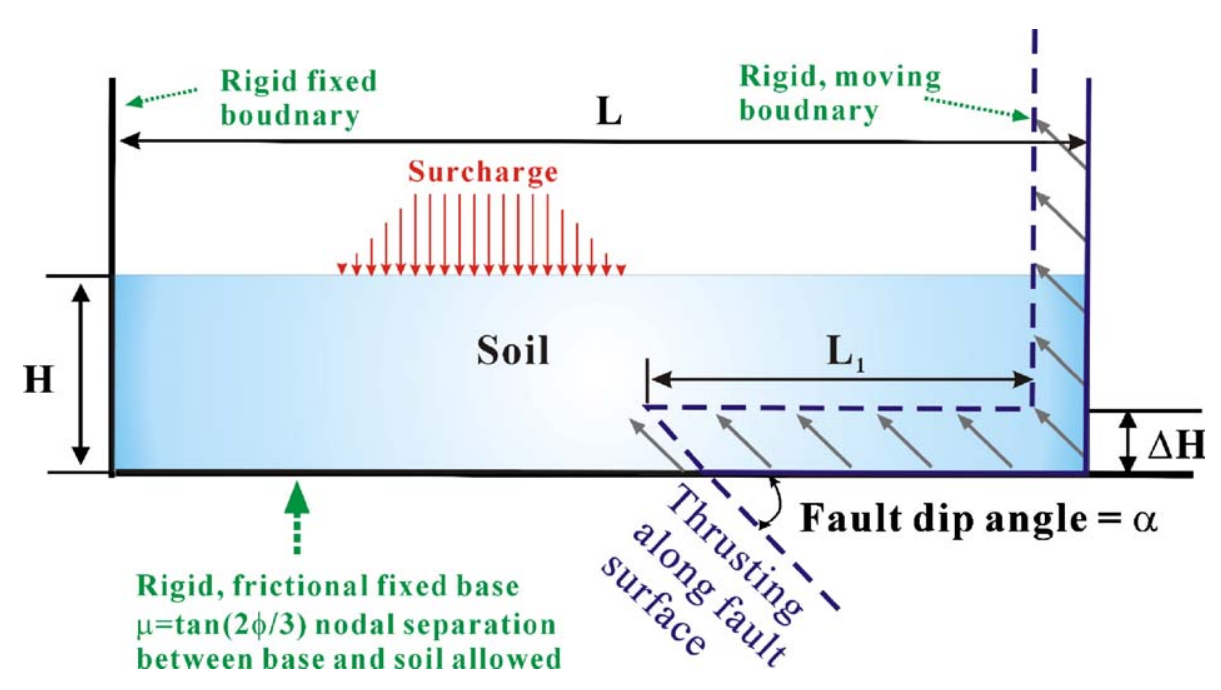

Fig. 6. Schematic setup of the numerical model. The right part is moved up obliquely to simulate uplift of a thrust fault on an inclined plane.

shear zone within shallow soil layers. A fault zone often developed within overburden soil, which is also a typical result from numerical simulations, when fault slip occurred, as shown in Fig. 5. The configuration and evolution of the shear zones obtained by the numerical analysis or by the sandbox test are consistent with one another.

Once results of the numerical simulation match with the physical modeling, a full-scale numerical model was established by changing the size of the numerical model. The dimensions for the small-scale and full-scale numerical models are summarized in Table 3. For the full-scale numerical model, several typical material properties of soils obtained from site investigation, instead of only the model sand, are used as input parameters (Chung et al., 2005). As such, the full-scale numerical analysis was aimed at simulating the deformation of full-scale strata rather than that of the small-scale model sand.

The influence of surcharge is evaluated by applying a vertical load with a width of $20 \mathrm{~m}$ at various locations on the ground surface. To avoid inducing singular points at the two edges when the vertical load is applied, the applied vertical load is selected to be $20 \mathrm{kN} / \mathrm{m}^{2}$ in the middle $10 \mathrm{~m}$ and gradually reduced to zero at the two edges of the applying width, as shown in Fig. 6.

\subsection{Trishear model of deformation}

A trishear model has been proposed (Erslev, 1991; Zehnder and Allmendinger, 2000; Champion et al., 2001; Johnson and Johnson, 2002; Finch et al., 2003; Cardozo et al., 2003; Chen et al., 2004) to simulate the evolution of the shear deformation induced by thrust fault slip.
During the deformation process, the trishear model conventionally assumes a constant $P / S$ ratio, where $P$ and $S$ are the amount of fault tip propagation and fault slip, and apical angle $2 \beta$, as defined in Fig. 7. The apical angle determines the range of deformation and a greater apical angle renders a greater trishear deformational zone as well as a lower strain level within the deformation zone. The material located within the footwall, which is alongside the trishear zone, remains fixed. During the faulting process, the trishear zone is always bounded by an upper boundary and a lower boundary, as depicted in Fig. 7. The ground surface movement of the hanging wall (far away from the trishear zone) is equal to the fault slip, as $S$ indicated in Fig. 7, and the uplift (the vertical component of $S$ ) of the ground surface along the hanging wall side is indicated as $S_{\mathrm{v}}$. The fault slip $S$ can often be smaller than the fault tip propagation $P$ so that the ratio is often greater than 1 .

Simply by observing the distorted dyed layer, the exact fault dip and fault zone within the soil strata are difficult to clearly identify in the sandbox experiments.

Table 3

Summary of the model dimension

\begin{tabular}{lllll}
\hline Dimension & $\begin{array}{l}\text { Sandbox } \\
\text { model }\end{array}$ & $\begin{array}{l}\text { Full-scale numerical } \\
\text { model }\end{array}$ & Unit \\
\cline { 3 - 4 } & & Case A & Case B & \\
\hline$L$ & 1 & 100 & 100 & $\mathrm{~m}$ \\
$L_{1}$ & 0.4 & 40 & 40 & $\mathrm{~m}$ \\
$H$ & 0.2 & 20 & 15 & $\mathrm{~m}$ \\
$\alpha$ & 50,60 & 60 & $30,60,90$ & Degree \\
$\Delta H / H$ & $30 \%$ & $15 \%$ & $15 \%$ & \\
\hline
\end{tabular}

Definition of $L, L_{1}, H, \alpha, \Delta H / H$ are shown in Fig. 6. 

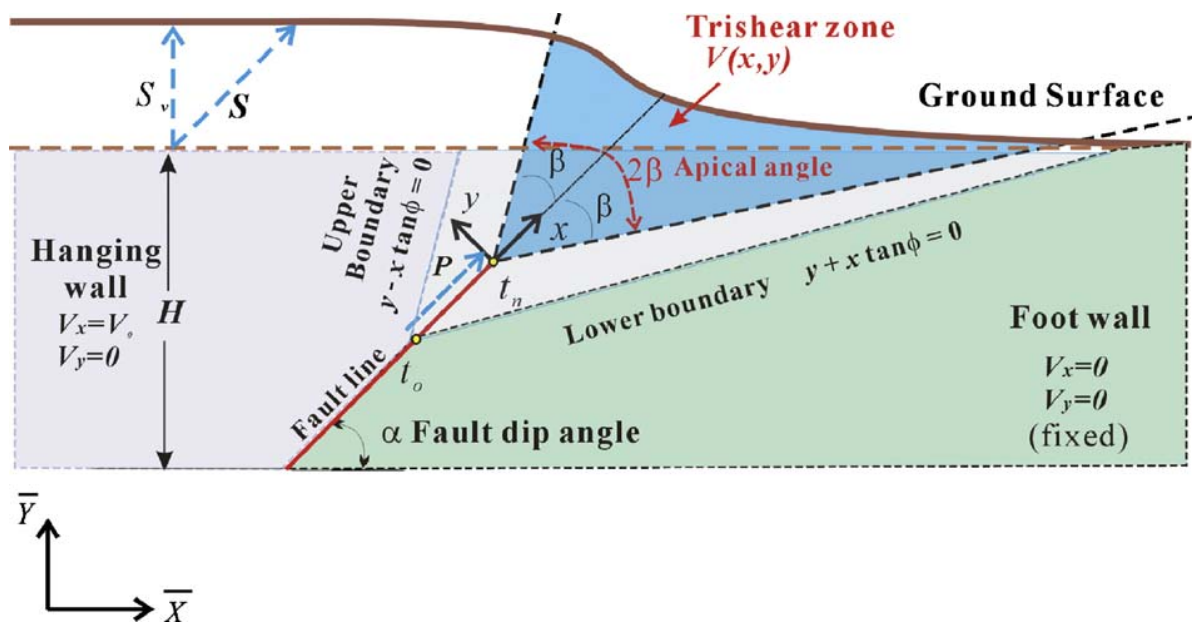

Fig. 7. Schematic illustration of the trishear model and corresponding definitions.

As such, the inverse analysis using trishear model was first conducted based on the geometry of folded strata as obtained by a particular sandbox experiment to locate the fault tip (Allmendinger, 1998; Zehnder and Allmendinger, 2000). Once the fault tip is located, a forward simulation is then conducted to obtain the predicted deformation of individual layers. As a result, the deformation produced by the sandbox experiment, numerical analysis and trishear model can be compared.

\section{Deformation of overburden soil-small-scale models}

When the hanging wall is uplifted for $0.3 H(6 \mathrm{~cm})$, the deformation of the overburden is as shown in Fig. 8a and $\mathrm{b}$, for fault dip angles of $50^{\circ}$ and $60^{\circ}$, respectively. Since the location where the fault trace would appear on the ground surface is of concern, a distance (denoted as $W$ ) is accordingly defined as the horizontal distance of the surface trace to the fault tip at the start of deformation, as shown in Fig. 12. Comparing Fig. 8a and $b$, it can be seen that a greater dip angle leads to a smaller $W$. This has been observed in previous work (Cole and Lade, 1984; Bray, 2001). Remarkably, more than one slip surface can be found in the major fault zone within the overburden soil; the primary slip surface is often accompanied by a secondary slip surface (denoted as numbers 1 and 2 in Fig. 8, respectively). Furthermore, comparing Fig. 8b with a, greater dip angles lead to a relatively narrower fault zone.

$W$ is also affected by the rate of uplifting; faster uplift leads to a smaller and narrower $W$, comparing Fig. $8 \mathrm{~b}$ with c. For the faster uplifting case, deformation is characterized by having a narrower fault zone and a steeper surface slope of $20^{\circ}$, comparing to $15^{\circ}$ as produced by the slower case. These facts imply that the slower uplifting rate allows more time for the sand to displace or to rotate such that convergence induced by fault slip is distributed and accommodated across a wider zone of soil.

The numerical simulation tends to have similar results as those of sandbox experiments, as compared in Fig. 9. A severely deformed shear zone was formed (right-hand side of Fig. 9), which resembles the fault zone found in the experiments (left-hand side of Fig. 9). A bifurcation of the fault zone into two branches can be observed when the dip angle is $50^{\circ}$, as shown in Fig. 10 . This result, several slip surfaces within a major fault zone, is similar to that of the sandbox tests and trench outcrops as shown in Figs. 8a and 2, respectively.

The material in the fault zone is found to behave plastically under failure, while adjacent material away from the fault zone remains elastic. According to the numerical analysis, one of the principal stresses near the ground surface is negative or under tension; this is supported by the fact that tensile cracks can be found on the field (Fig. 2; Bray, 2001; Champion et al., 2001; Lee et al., 2004). The surface slope near fault scarp obtained from experiments tends to be smoother than that obtained from the numerical simulation. Down-slope movement of sand down the surface scrap may account for such a lower slope.

Although the strength parameter or the deformation modulus of sand can be measured, another parameter, the dilation angle of plastic flow rule $\psi$, is difficult to constrain by simple experiments and thus requires numerical analysis to evaluate an adequate magnitude. With other properties of sand being the same, the 


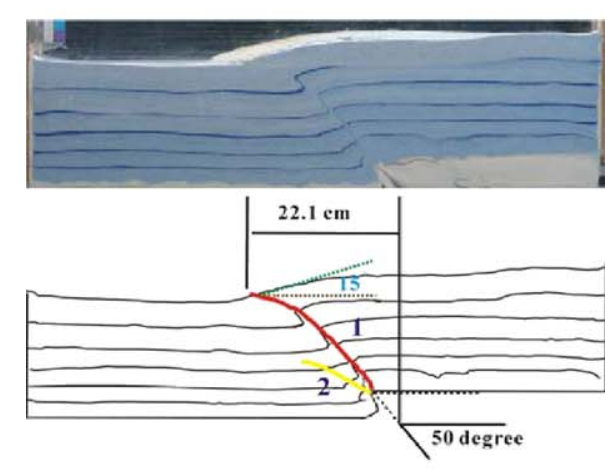

(a)

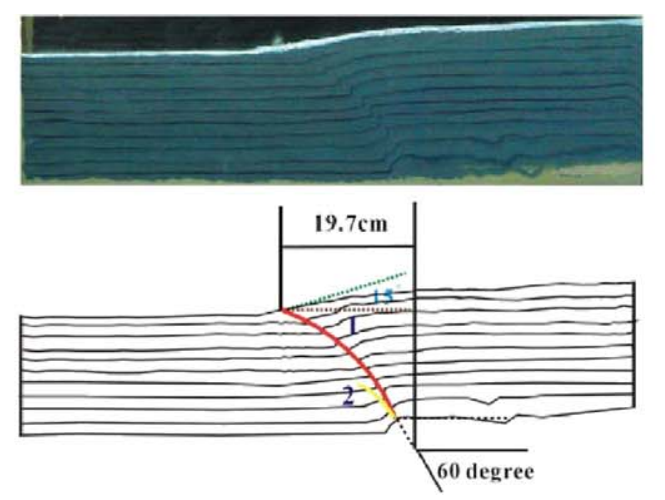

(b)

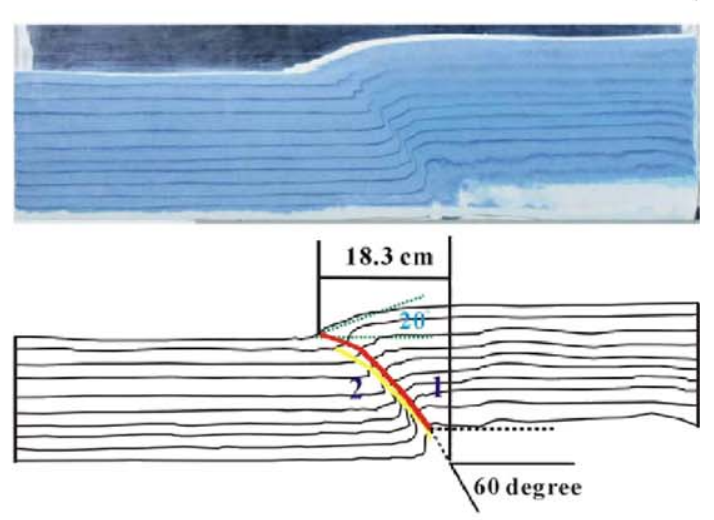

(c)

Fig. 8. Outcomes of the deformation motivated by faults with different dip angles and uplifting rates. (a) Dip angle $50^{\circ}$, slower uplifting rate with $\Delta H / H$ of $8.0 \times 10^{-3} \mathrm{~s}{ }^{-1}$; (b) dip angle $60^{\circ}$, slower uplifting rate with $\Delta H / H$ of $8.0 \times 10^{-3} \mathrm{~s}^{-1}$; (c) Dip angle $60^{\circ}$, faster uplifting rate with $\Delta H / H$ of $3.1 \times 10^{-2} \mathrm{~s}^{-1}$ 

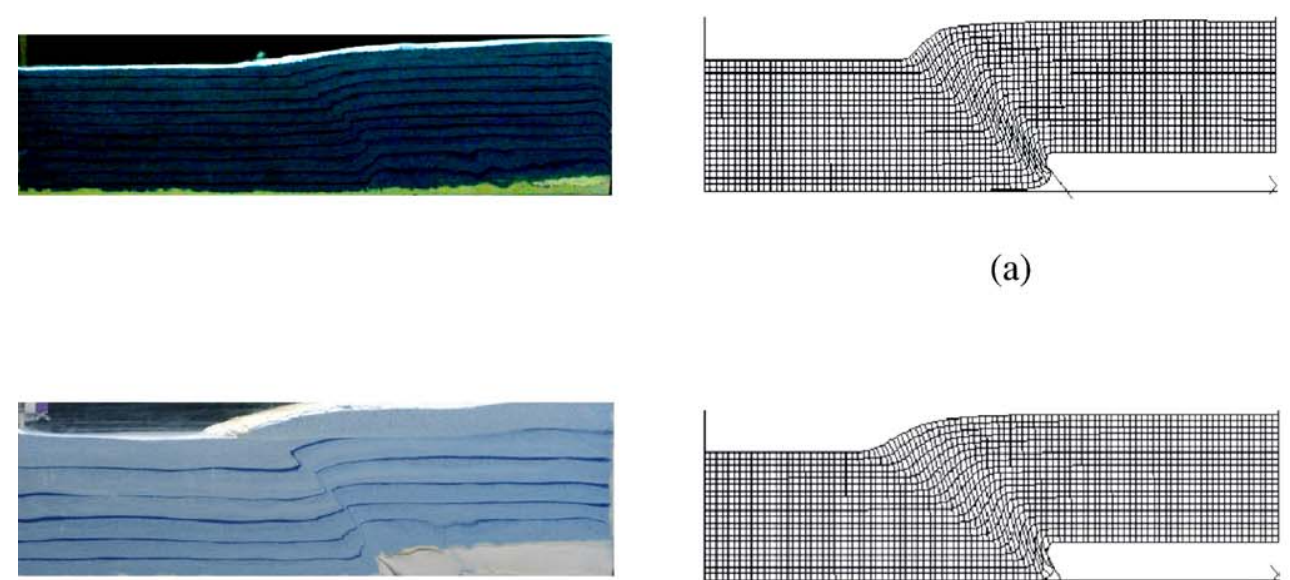

$20 \mathrm{~cm}$ (a)
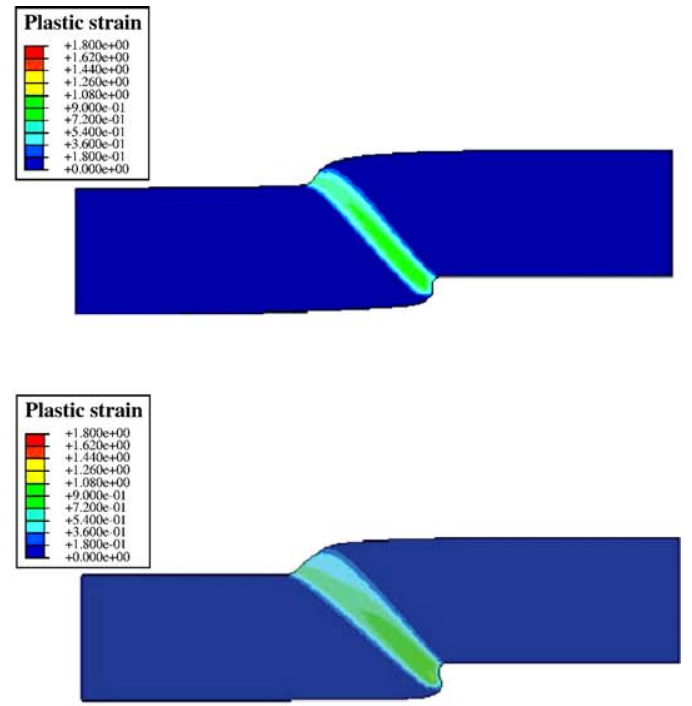

(b)

Fig. 9. Comparison of the fault yielded by the small-scale physical and numerical model. The contour in the right figure shows the magnitude of the plastic strain. The dark color area has no plastic strain. The soil within the light color zones has failed and thus experiences plastic strain. Therefore, the light color zone represents the fault zone within the overburden soil. (a) Fault dip angle $60^{\circ}$. (b) Fault dip angle $50^{\circ}$. 


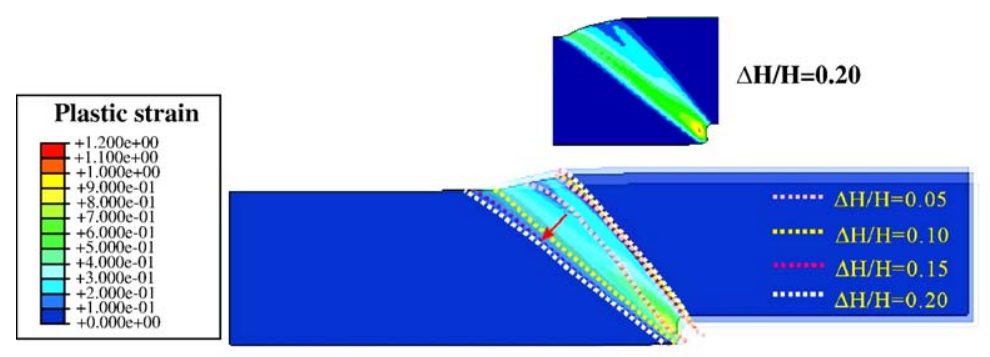

(a)

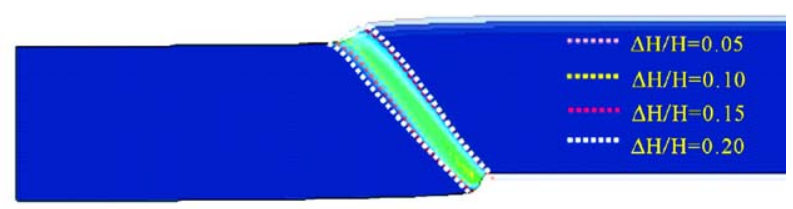

(b)

Fig. 10. Migration of plastic shear zones induced by the basement uplift with a different dip angle. (Overlap of four stages of fault slip, the plastic zone bifurcates into two branches when the base uplift, $\Delta H / H=0.20$ for fault dip angle $50^{\circ}$ case.) (a) Fault dip angle $50^{\circ}$. (b)Fault dip angle $60^{\circ}$.

dilation angle $\psi$ for the numerical analyses is accordingly determined as $6^{\circ}$, by adjusting the numerical results to have the same $W$ with the experimental results.

Fig. 11 illustrates the effect of varying $\psi$ on the fault in the overburden soil. A greater $\psi$ leads to a greater $W$, a wider fault zone, a smaller degree of plastic deformation and a lower surface slope of fault scarp.

Cole and Lade (1984) found that an increase in dip angle $\alpha$ would result in a greater $W$, and proposed a $W / H$ versus $\alpha$ relationship, as shown in Fig. 12. They also found that a greater $\psi$ would lead to a greater $W / H$. For the model cases, the $\mathrm{W} / \mathrm{H}$ obtained by both experiments and numerical simulation compares well with Cole and Lade's observation, as shown in Fig. 12. Other cases, including the results of the full-scale model, are also presented in Fig. 12, which are discussed later.

\section{Deformation of overburden soil-full-scale numerical model}

Since overburden sand in the full-scale model has a thickness of tens of meters (Table 3), the resulting overburden pressure compresses the sand such that it cannot possibly be as loose as the sand in the model case. Therefore, the Young's modulus and the unit weight of sand in the full-scale model are increased to $5 \mathrm{MPa}$ and $20 \mathrm{kN} / \mathrm{m}^{3}$, respectively. Besides the above-mentioned adjustments based on the calibrated small-scale numerical model, the remaining properties of sand used in the small-scale model are also used in the full-scale model.
As such, a series of parametric studies were performed to study their influence on faulting behavior.

The fault zones developed in the overburden soil subjected to various dip angles of thrust fault slip are shown in Fig. 13. Upon subsequent fault slip, the fault zone propagates upward into the overburden soil, at a lower dip angle, as shown in Fig. 13. The dip angle in soil progressively decreases towards ground surface, which has been observed in the field (Fig. 2; Lade et al., 1984; Bray et al., 1994a; Chen et al., 2001, 2004; Lee et al., 2004), and in the laboratory experiments (Fig. 8; Cole and Lade, 1984; Tani et al., 1994; Bray et al., 1994b; Lee and Hamada, 2005; Lin et al., 2005a).

Compared to the small-scale model, the full-scale model includes a major fault zone, surface tension and a similar trend in the increase of $W$ with decreasing dip angles. For the full-scale model, the impact of $\psi$ on $W / H$ is even more significant, as shown in Fig. 12. For $\psi$ ranging from $6^{\circ}$ to $30^{\circ}$, the increase of $W / H$ ratio exceeds 0.5 .

Comparing Fig. 9a with Fig. 13b, minor differences in the deformation pattern and the development of plastic strain can still be found. What accounts for such discrepancy, the so-called scale effect, will be discussed in later sections.

Remarkably, when the dip angle is $90^{\circ}$, as shown in Fig. 13c, two surface failure zones were induced by surface tensile stress at both the footwall and the hanging wall. This is a result of relatively steeper surface slope induced in this case. 


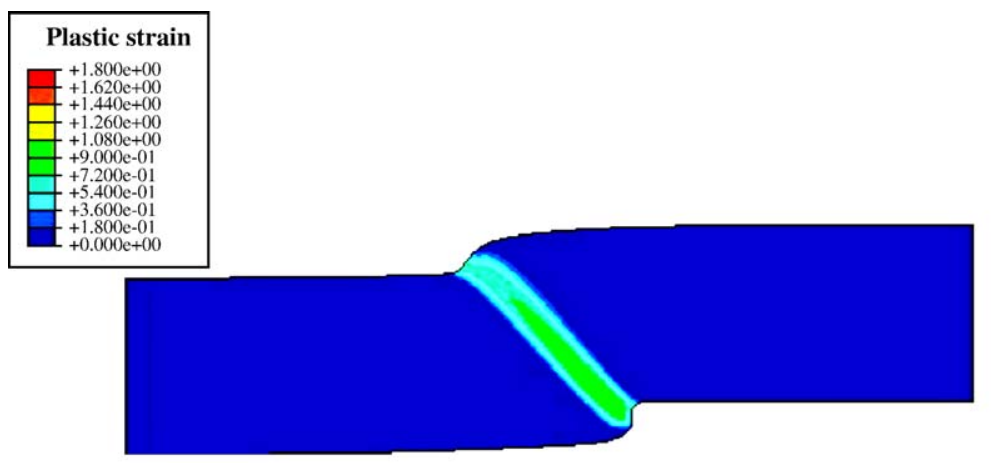

(a) $\psi=6^{\circ}$

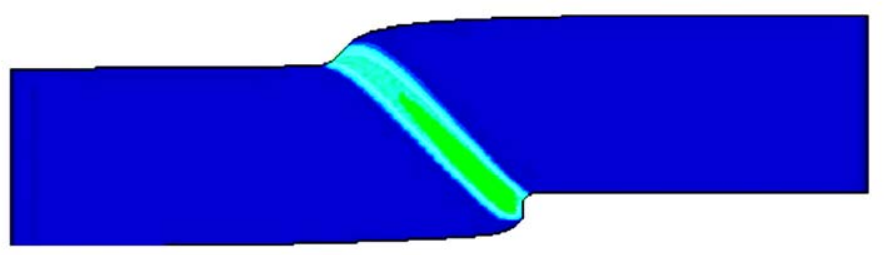

(b) $\psi=10^{\circ}$

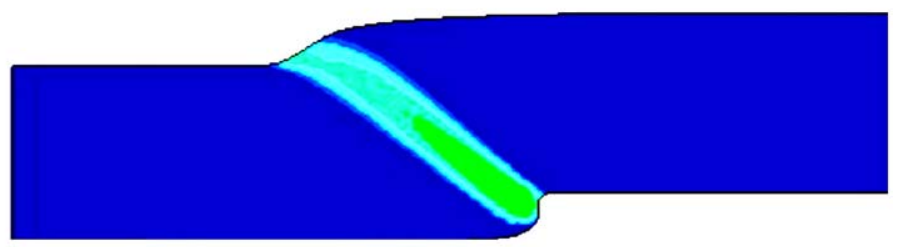

(c) $\psi=20^{\circ}$

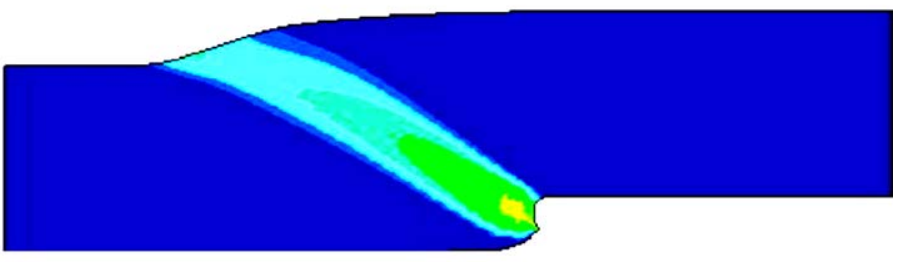

(d) $\psi=30^{\circ}$

Fig. 11. Influence of dilation angle $\psi$. The results are obtained by the small-scale, numerical simulation.

The ground is often composed of sand and clay layers and could have some cohesion. Therefore, soil with the cohesion strength is considered in the analyses. Meanwhile, if cohesion is selected to be zero in the material model, simulating sand, the ground surface would have a large region of a plastic zone, which often leads to numerical difficulties and a computational result may diverge. To accommodate these difficulties, minor cohesion is sometimes applied to obtain a convergent result.

When the soil has a normal Young's modulus (e.g., $5 \mathrm{MPa}$ ), a single fault zone develops as mentioned previously (Fig. 14a). However, if the ground is hardened, possibly by a manual compaction or by a seasonal fluctuation of the ground water level, not only a greater $W$ will be resulted but also a back-thrust can be formed, as shown in Fig. 14b. When the soil is stiff and deformed by the same amount of uplift, more stress will be induced within the soil body and the sufficiently large accumulated stress induces a pair of conjugate failure (fault) zones, which accounts for the occurrence of the back-thrust. Back-thrusts were not found in the smallscale models, since it was difficult to increase Young's modulus without changing other material parameters. However, back-thrusts, the coseismic deformations of the Chichi earthquake in 1999, were observed in middle Taiwan (Kelson et al., 2001; Dong et al., 2003; Lee 


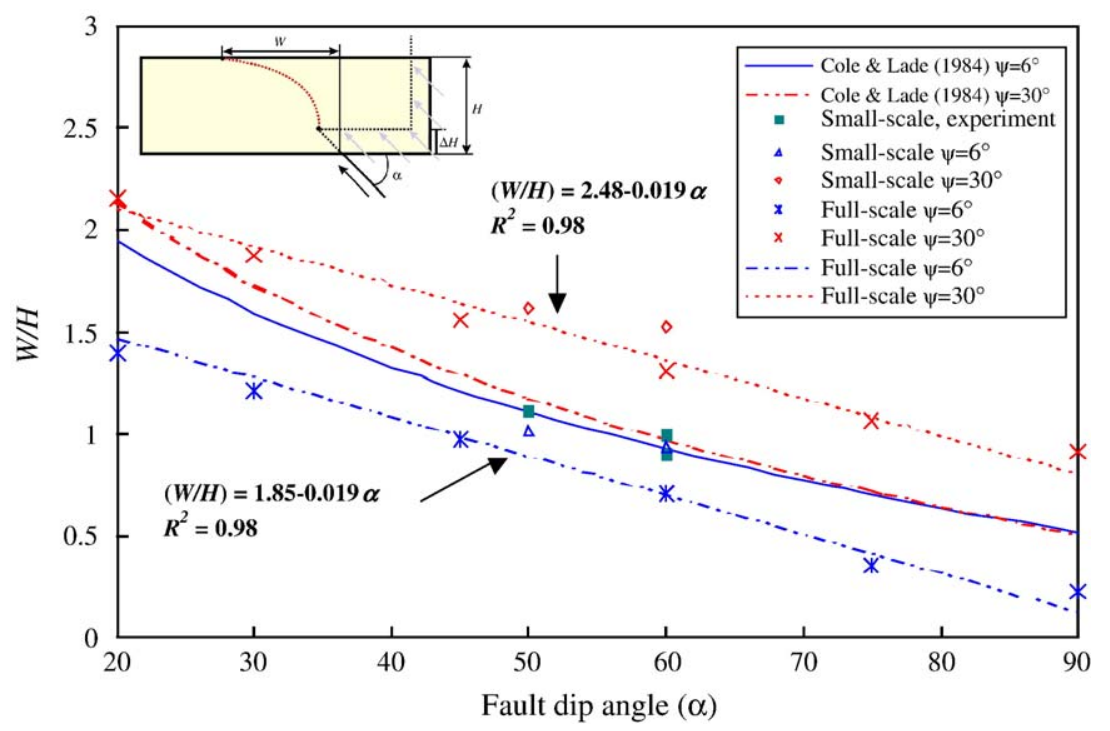

Fig. 12. Variation of $W / H$ with fault dip angle $\alpha$. The definitions of $W, H$ and $\Delta H$ are indicated in the inset.

et al., 2004; Ota et al., 2005). Therefore, the possible occurrence of back-thrusts requires attention (Roering et al., 1997; Nino et al., 1998; Schultz, 2000).

Alternatively, the influence of Poisson's ratio tends to be less significant. A greater Poisson's ratio, which implies that compression in one direction will lead to more lateral deformation in another direction, tends to result in a slightly wider fault zone, as seen by comparison of Fig. 14c with Fig. 14a.

Stronger cohesion, as shown in Fig. 14a and d, results in greater strength and leads to a smaller surface tensile failure zone as well as a smaller distance of fault tip propagation. As shown in Fig. 14d, the shear zone (or the fault tip) propagates and rests in the middle of soil. As such, stronger strength prevents the coalescence of the underlying fault tip with the near surface tensile failure zone in forming a complete fault surface reaching the ground surface.

In the numerical analysis, tensile stress was obtained near the ground surface owing to the adopted material model, which is an elasto-plastic model and is a simplified material model for soil. As for sand, since it does not have cohesion strength, it cannot sustain any tensile stress. Therefore, discrepancy induced by cohesion needs to be studied and a parametric study regarding the influence of cohesion has been conducted as shown in Fig. 14d. It was found that the influence of cohesion is minor when compared to the influence of Young's modulus.

Another strength parameter, the friction angle $\phi$, has a similar effect in suppressing development of a fault zone. As shown in Fig. 14a and e, a greater $\phi$, which increases the strength of soil, prevents propagation of the fault tip from reaching the ground surface. The surface tensile failure zone for the greater $\phi$ case tends to be relatively greater. For the greater $\phi$ case, deformation in the middle section of the fault zone is prevented and the deformation is thus distributed over a wider surface area, which possibly accounts for the wider surface failure zone formed under tension.

The surcharge, with a maximum magnitude of $20 \mathrm{kPa}$, on the ground surface (e.g. the loads applied by the weight of ground structures) has a significant influence on the development of fault zones, as shown in Fig. 15. The surcharge directly suppresses the occurrence of underlying surface tension. Depending on the location where the surcharge is applied, the original fault zone is either forced to move to the corner of the surcharge (Fig. 15a and b), or propagation of the fault tip is prevented from reaching the ground surface (Fig. 15c). In actuality, it has been reported that the development of fault trace on the ground surface can be diverted owing to the existence of the building (Bray, 2001; Kelson et al., 2001; Hitchcock et al., 2001; Dong et al., 2003; Anastasopoulos, 2005), which is similar to the results of the numerical simulation in this research (Anastasopoulos, 2005).

The development of a fault zone within the soil increases with the amount of uplift of the hanging wall, as shown in Fig. 16, where both the height of fault zone $h$ and the amount of uplift $\Delta H$ are normalized by the height of the soil stratum $H$. As shown in Fig. 16, models indicate that, for $\alpha$ greater than $45^{\circ}$, the fault zone may reach the ground surface when $\Delta H / H$ is about 


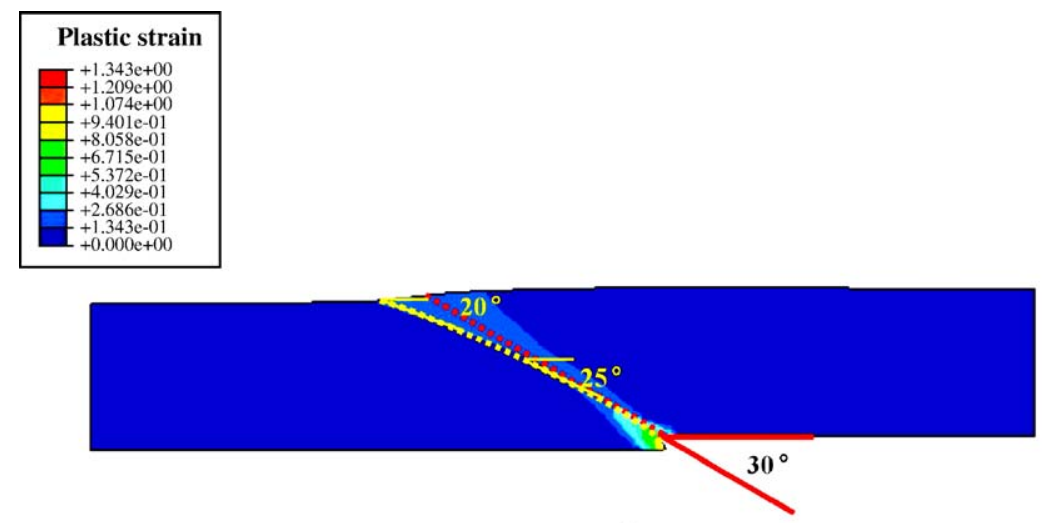

(a) $\alpha=30^{\circ}$

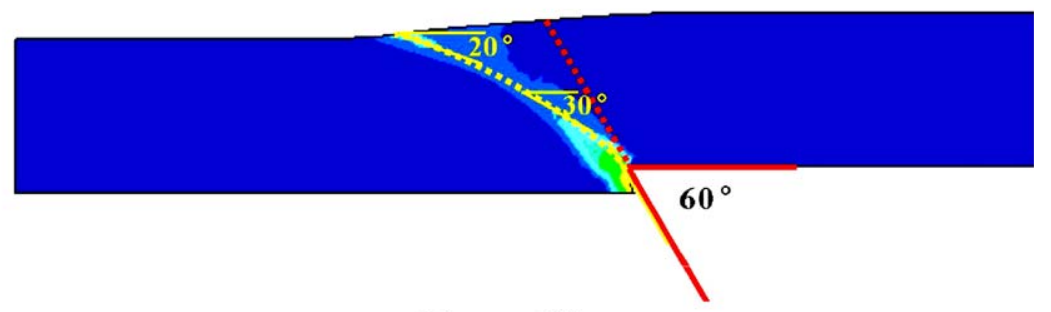

(b) $\alpha=60^{\circ}$

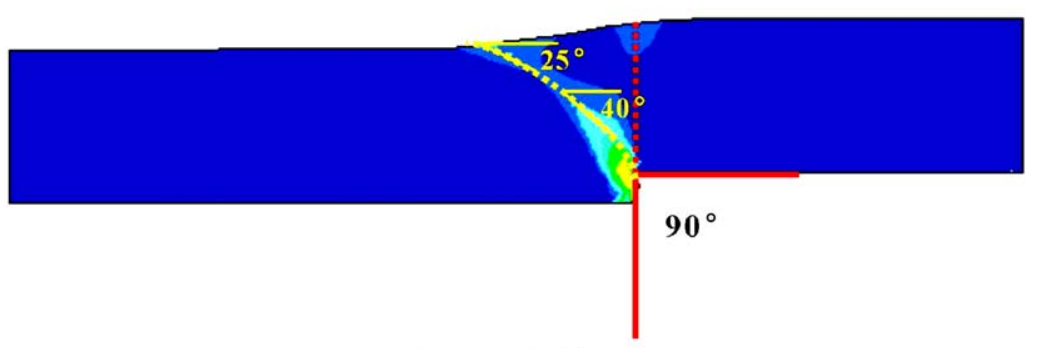

(c) $\alpha=90^{\circ}$

Fig. 13. Deformation of the full-scale model induced by the thrust fault with varying dip angles. The dip angle within the overburden soil is less than that of the embedded fault and keeps decreasing from the bottom to the top surface. The light color zone is the plastic zone.

0.9. In such circumstance, the underlying shear fault zone coalescences with the surface tensile zone and becomes a complete fault zone. As a result, the underground shear fault zone takes about $60-70 \%$ of the height of overburden soil. Where $\alpha$ is less than $45^{\circ}$, the required $\Delta H / H$ is about $30 \%$ greater, the underground shear fault zone produces 0.12 , compared to 0.9 , and $90 \%$ of the height of the fault zone.

\section{Discussion}

\subsection{Scale effect}

For the small-scale model and the full-scale model, differences that occur for the fault zones are apparent within the overburden soil. Comparing Figs. 9a and 13b, the geometry of fault zones is somewhat different. Moreover, the obtained $W / H$ of the full-scale model differs from that of small-scale model, as shown in Fig. 12. Namely, the scale effect exists and its mechanism requires further consideration. It has been suggested that, if the sand is thick enough, the scale effect is less significant (Tani et al., 1994; Bray, 1994b; Lee and Hamada, 2005). Meanwhile, the authors (Lin et al., 2005b) studied the scale effect based on $1 \mathrm{~g}$ and $20 \mathrm{~g}$ centrifugal tests, and found that the stiffness of sand and basal friction may also contribute to contrasting results at different scales.

The material properties, the Young's modulus, and unit weight of sand in the full-scale model differ from 

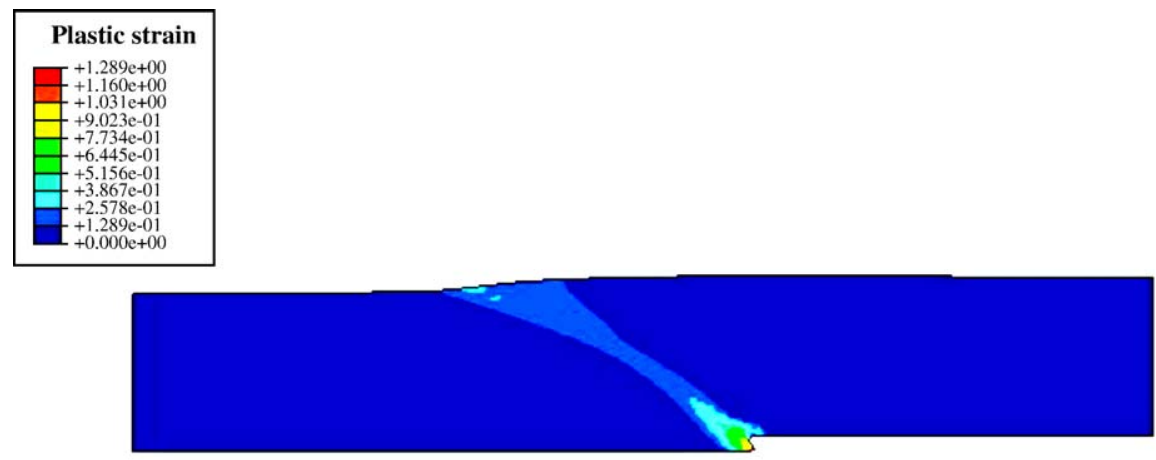

(a)

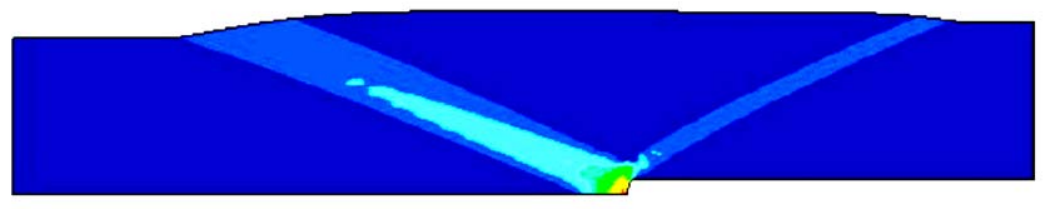

(b)

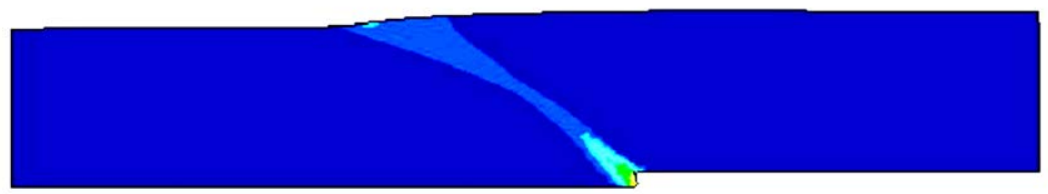

(c)

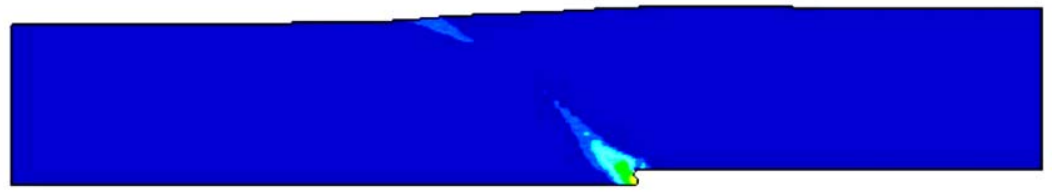

(d)

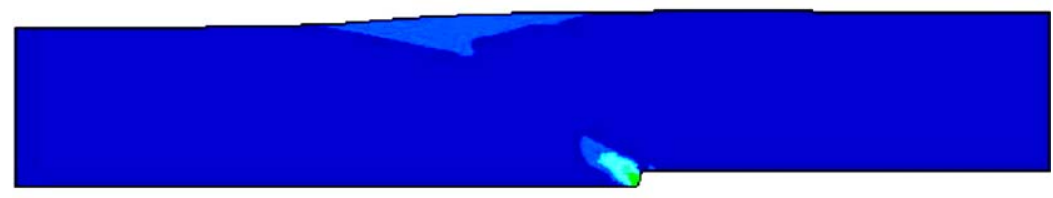

(e)

Fig. 14. Influence of the factor, including Young's modulus $E$, Poisson's ratio, cohesion strength $c$, friction angle $\phi$, on the yielded fault zone within the overburden soil. Full-scale model with fault dip angle $\alpha=30^{\circ}$. The light color zone is the plastic zone. (a) $E=5 \mathrm{MPa}, v=0.4, c=5 \mathrm{kPa}, \phi=30^{\circ}$. (b) $E=50 \mathrm{MPa}, v=0.4, c=5 \mathrm{kPa}, \phi=30^{\circ}$. (c) $E=5 \mathrm{MPa}, v=0.3, c=5 \mathrm{kPa}, \phi=30^{\circ}$. (d) $E=5 \mathrm{MPa}, v=0.4, c=50 \mathrm{kPa}, \phi=30^{\circ}$. (e) $E=5 \mathrm{MPa}$, $\nu=0.4, c=5 \mathrm{kPa}, \phi=40^{\circ}$.

those of the small-scale model. As shown in Fig. 17a and $b$, if the full-scale model adopted the Young's modulus of the small-scale model, 1.29 MPa, a complete fault zone would not develop. Whereas, a complete fault would be developed when the in situ Young's modulus, $5 \mathrm{MPa}$, is applied as shown in Fig. 17d. The scale difference is 1 to 100 , yet the ratio of $E_{\text {full-scale }} / E_{\text {small-scale }}$ is about 4, so as to yield a complete fault zone. This phenomenon indicates that:

1. To enable a physical, small-scale simulation to corectly model the full-scale behavior, Young's modulus should be decreased. The magnitude of lowering should be carefully determined, by matching the 


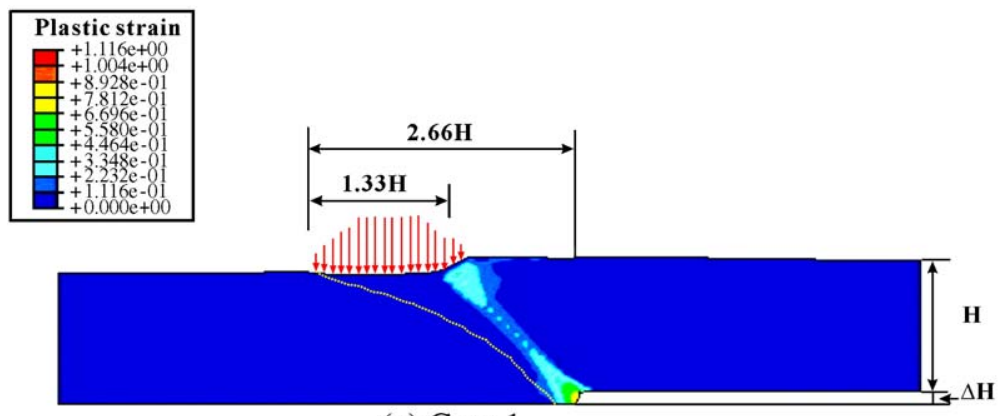

(a) Case 1

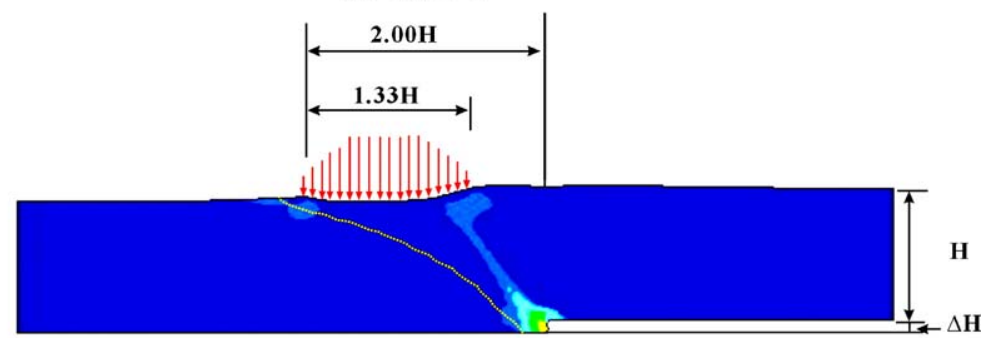

(b) Case 2

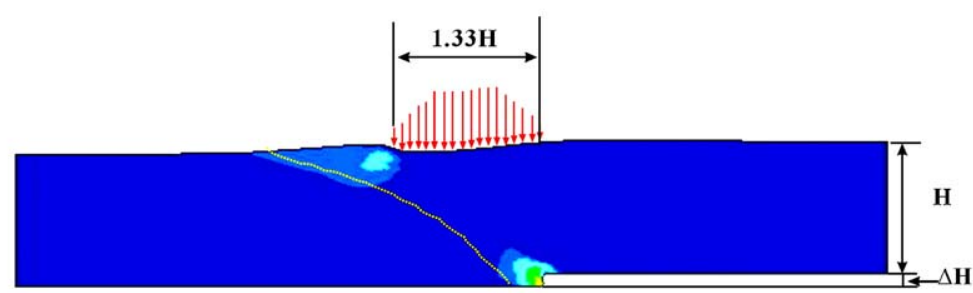

(c) Case 3

Fig. 15. Influence of the surcharge on the yielded fault zone within the overburden soil. Full-scale model. The light color zone is the plastic zone. The surcharge has a width of $1.33 \mathrm{H}$ and a maximum magnitude of $20 \mathrm{kPa}$.

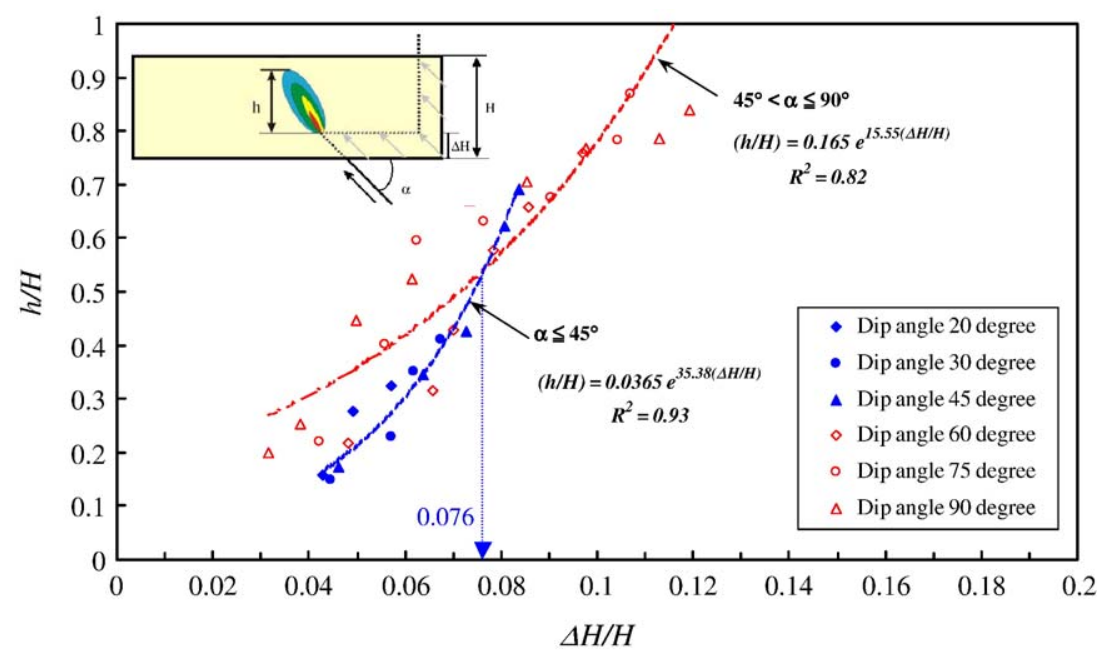

Fig. 16. Development of the fault upon increasing uplift, $\Delta H / H$. The height of the location of fault tip is indicated by $h$, as indicated in the inset, and the maximum height is thus $H-\Delta H$. 


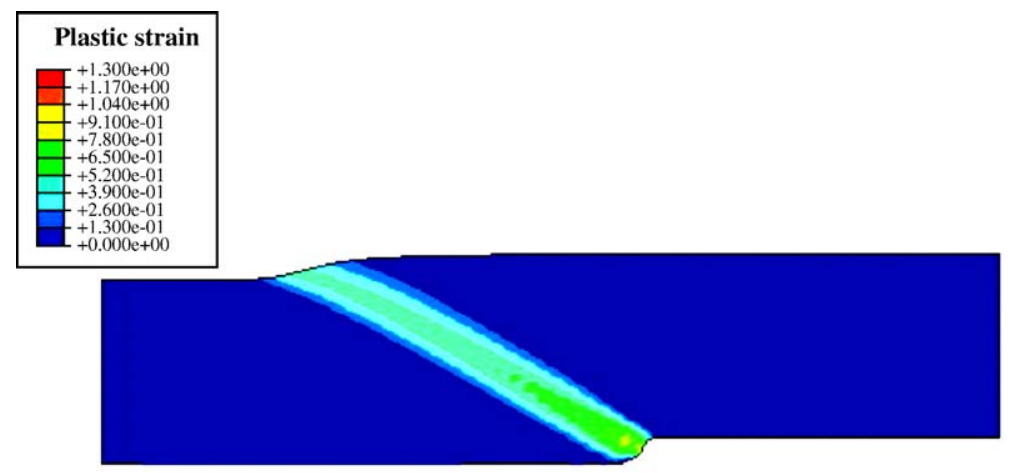

(a)

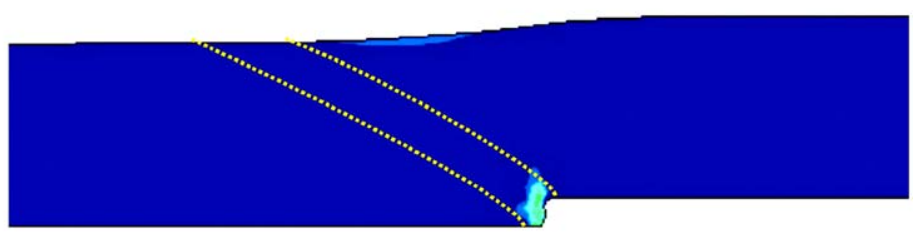

(b)

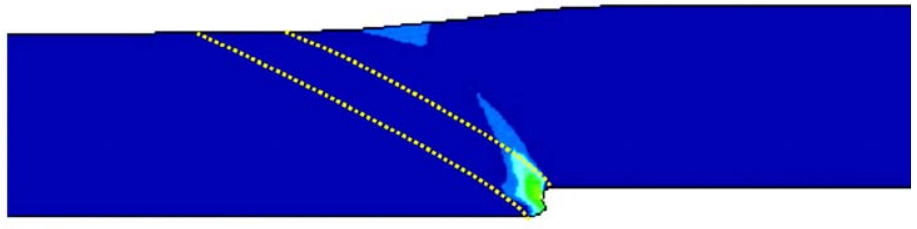

(c)

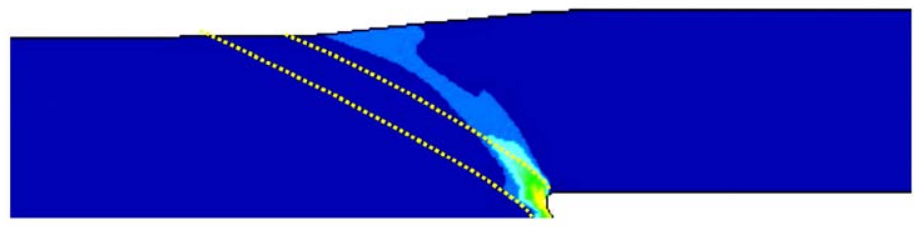

(d)

Fig. 17. Outcome of the deformation induced under various scales and Young's modulus $E$. Base set of parameters: fault dip angle $\alpha=60^{\circ}$, $\gamma=15.7 \mathrm{kN} / \mathrm{m}^{3}, v=0.4, c=5 \mathrm{kPa}, \phi=30^{\circ}, \psi=30^{\circ}, K_{0}=0.5, \Delta H / H=0.15$. (a) Small-scale; $E=1.29 \mathrm{MPa}$. (b) Full-scale; $E=1.29 \mathrm{MPa}$. (c) Full-scale; $E=3.00 \mathrm{MPa}$. (d) Full-scale; $E=5.00 \mathrm{MPa}$.

results of model with those of actual deformation found by trench excavation.

2. Differences may still exist for the geometry of the fault zone and the $W / H$ ratio, as shown in Fig. 17. Namely, provided a proper softening of $E$ has been applied, the $W / H$ predicted by the physical, smallscale model may not be completely appropriate and should be used cautiously.

\subsection{Trishear model of deformation}

Based on the experimental results as shown in Fig. 5, the deformation features within the overburden soil include the monoclinal morphological features of ground surface and beddings, downward steepening of forelimb strata, and smoothly rounded fold-hinges which are consistent with a trishear fault-propagation fold growth above a blind thrust. The best-fit parameters of $P / S$ ratio and apical angle $2 \beta$ are shown in Fig. 18. Overall, the deformation of the overburden soil simulated by the trishear model is consistent with that produced by sandbox experiments as compared in Fig. 18. The best-fit dip angle in the soil is found to be $50^{\circ}$, which is smaller than the dip angle, $60^{\circ}$, of the basement fault. Furthermore, during the deformation process, the apical angle and the $P / S$ ratio progressively 


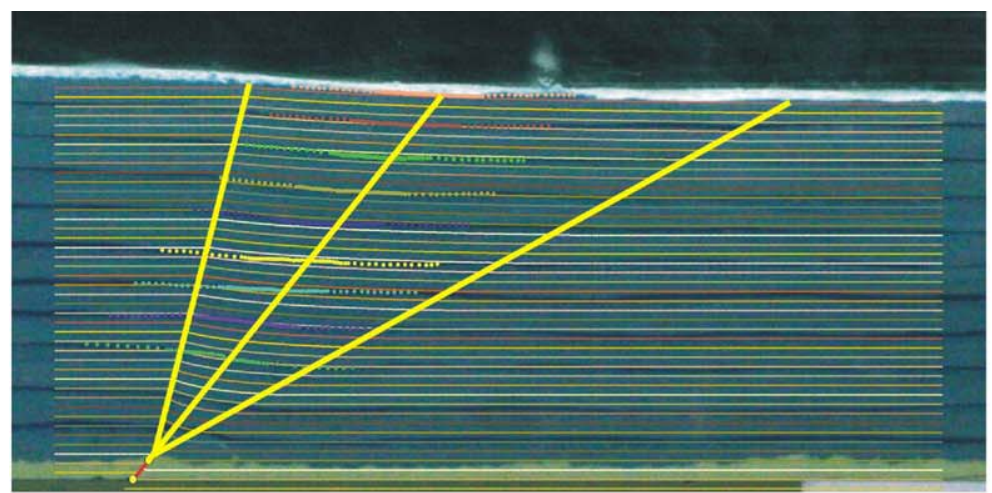

(a) $\Delta H / H=0.04, P / S=1.0$, apical angle $2 \beta=46^{\circ}, \alpha=60^{\circ}, \alpha^{\prime}=50^{\circ}$

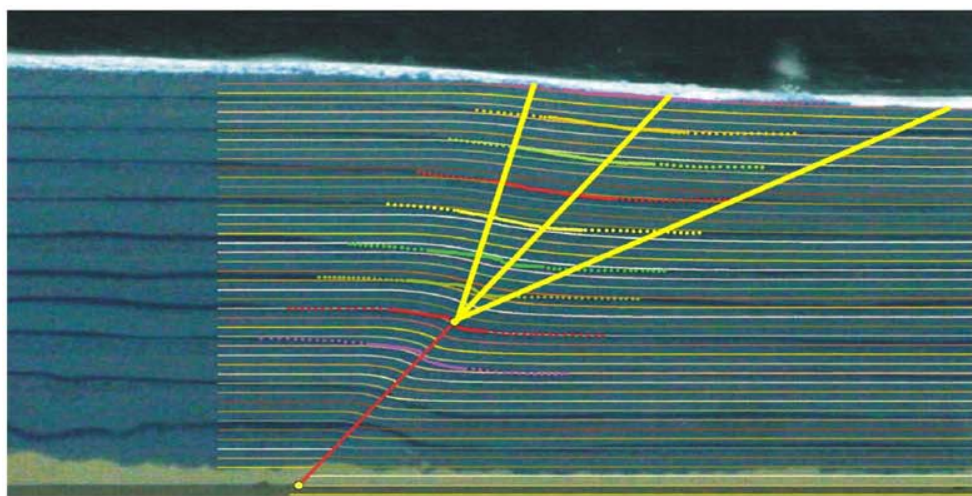

(b) $\Delta H / H=0.08, P / S=6.0$, apical angle $2 \beta=48^{\circ}, \alpha=60^{\circ}, \alpha^{\prime}=50^{\circ}$

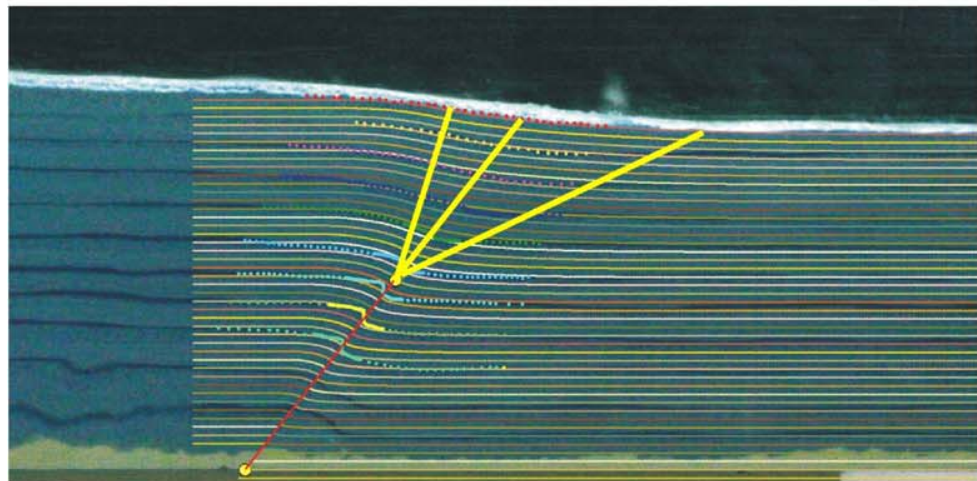

(c) $\Delta H / H=0.10, P / S=5.5$, apical angle $2 \beta=52^{\circ}, \alpha=60^{\circ}, \alpha^{\prime}=50^{\circ}$

Fig. 18. The best-fit deformation using the trishear model and corresponding determined parameters.

increase from $46^{\circ}$ to $52^{\circ}$ and 1 to 5.5 , respectively. Similar deformational behavior has also been observed through the numerical simulation, as shown in Fig. 13. The deformation fields of the overburden soil, obtained by physical experiments, mechanical model (the finite element analysis) and kinematic model (trishear model), show a close resemblance to each other.

\section{Conclusion}

The influence of uplifting rate, fault dip angle, dilation angle of plastic flow, scale effect, Young's modulus, Poisson ratio, cohesive strength, frictional angle and the location of surcharge are studied. Among these factors, it is found that Young's modulus and the dilation angle of 
plastic flow most strongly influence near surface faulting in soil. A greater dilation angle leads to a smaller fault propagation distance, the $W$ defined in Fig. 12, and a wider fault zone. A stiffer $E$ leads to early development of fault propagation and possible occurrence of backthrust. Most importantly, given the same Young's modulus, fault development can significantly differ for the small-scale and the full-scale models. Accordingly, to have a similar faulting behavior, Young's modulus of the small-scale model soil should be scaled down several times from that of full-scale in-situ soil.

Whether the back-thrust may or may not occur depends on the configuration of blind fault and the properties of overburden. Given the fact that the back-thrust has been observed (Kelson et al., 2001; Dong et al., 2003; Lee et al., 2004; Ota et al., 2005, etc.), the possibility of the occurrence of the back-thrust should be considered. However, more sophisticated material models should be done to clarify under what circumstances the back-thrust will happen.

Such phenomena highlight that cautious evaluation of these two parameters is essential in order to properly simulate or predict fault development and the deformation process. Meanwhile, when the small-scale physical model is used to simulate the fault development for a full-scale problem, the stiffness of the model soil should be properly scaled down, which still awaits further study.

The development of a branching thrust fault, which is often difficult to simulate by numerical methods such as the finite element method, calls attention to estimates of the size of the influential zone. Last but not least, the surcharge, depending on its location and magnitude, may effectively suppress the occurrence of thrust faults or change the location of the fault.

The trishear model has served as a convenient tool for assessing deformation and fault propagation within overburden soil. As revealed by both experimental and numerical studies, if the $P / S$ ratio, apical angle and dip angle were allowed to vary during deformational processes, it might enable a more precise simulation of trishear model based on current theory.

To properly simulate or predict the deformation process within overburden soil, both physical and numerical models are required to produce a more realistic simulation of faulting and show its influence on important manmade infrastructure.

\section{Acknowledgement}

The research is mainly supported by Moh and Associate, Inc. and partly supported by the National Science
Council of Taiwan, Grant Nos. NSC-90-2211-E-002-095, and NSC-91-2211-E-002-048. The advice, comments and help provided by the editor, Dr. Karl Mueller, and another anonymous reviewer have significantly strengthened the scientific soundness of this paper. Their kind efforts are gratefully acknowledged.

\section{References}

Allmendinger, R.W., 1998. Inverse and forward numerical modeling of trishear fault-propagation folds. Tectonics 17, 640-656.

Anastasopoulos, I., 2005. Behaviour of foundations over surface fault rupture: analysis of case histories from the Izmit (1999) earthquake. Proceedings of the 16th international conference on soil mechanics and geotechnical, Osaka, Japan, pp. 2623-2626.

Backblom, G., Munier, R., 2002. Effects of earthquakes on the deep repository for spent fuel in Sweden based on case studies and preliminary model results. SKB Technical Report TR-02-24. Swedish Nuclear Fuel and Waste Management Co., Stockholm Sweden.

Bray, J.D., Seed, R.B., Cluff, L.S., Seed, H.B., 1994a. Earthquake fault rupture propagation through soil. Journal of Geotechnical Engineering 120, 543-561.

Bray, J.D., Seed, R.B., Seed, H.B., 1994b. Analysis of earthquake fault ruptures propagation through cohesive soil. Journal of Geotechnical Engineering 120, 562-580.

Bray, J.D., 2001. Developing mitigation measures for the hazards associated with earthquake surface fault rupture. Proceedings of Workshop on Seismic Fault-Induced Failures, Tokyo, pp. 55-80.

Bonilla, M.G., 1982. Evaluation of potential surface faulting and other tectonic deformation. U.S. Geological Survey, Open-File, pp. $82-732$.

Cardozo, N., Bhalla, K., Zehnder, A.T., Allmendinger, R.W., 2003. Mechanical models of fault propagation folds and comparison to the trishear kinematic model. Journal of Structural Geology 25, 1-18.

Champion, J., Mueller, K., Tate, A., Guccione, M., 2001. Geometry, numerical models and revised slip rate for the Reelfoot fault and trishear fault-propagation fold, New Madrid seismic zone. Engineering Geology 62, 31-49.

Chen, W.S., Huang, B.S., Chen, Y.G., Lee, Y.H., Yang, C.N., Lo, C.H., Chang, H.C., Sung, Q.C., Hiang, N.W., Lin, C.C., Sung, S.H., Lee, K.J., 2001. 1999 Chi-Chi earthquake: a case study on the role of thrust-ramp structures for generating earthquakes. Bulletin Seismological of America 91, 986-994.

Chen, W.S., Lee, K.j., Lee, L.S., Ponti, D.J., Prentice, C., Chen, Y.G., Chang, H.C., Lee, Y.H., 2004. Slip rate and recurrence interval of the Chelungpu Fault during the past 1900 years. Quaternary International 115-116, 167-176.

Chen, W.S., Lee, L.S., Lee, K.J., Yang, H.C., Yang, C.C., Chang, H.C., Ota, Y., Lin, C.W., Lin, W.H., Shin, T.S., Lu, S.T., submitted for publication. Paleoearthquakes and Slip Rate of the Chelungpu Fault, Central Taiwan: the 1999 Chichi earthquake rupture. Bulletin of the Seismological Society of America.

Chung, C.F., Lin, M.L., Jeng, F.S., Tsai, L.S., Chin, C.T., Chan, S.J., 2005. A case study on the response of shield tunnel near a thrust fault offset. Proceedings of Geotechnical Earthquake Engineering Satellite Conference, Osaka, Japan.

Cole, D.A., Lade, P.V., 1984. Influence zones in alluvium over dip-slip faults. Journal of Geotechnical Engineering 110, 599-615.

Dong, J.J., Wang, C.D., Lee, C.T., Liao, J.J., Pan, Y.W., 2003. The influence of surface ruptures on building damage in 1999 Chi-Chi 
earthquake: a case study in Fengyuan city. Engineering Geology 71, 157-179.

Duncan, J.M., Lefebvre, G., 1973. Earth pressures on structures due to fault movement. Journal of Soil Mechanics and Foundation Division, ASCE 99 (SM12), 1153-1163.

Erickson, S.G., Strayer, L.M., Suppe, J., 2001. Initiation and reactivation of faults during movement over a thrust-fault ramp numerical mechanical models. Journal of Structural Geology 23, $11-23$.

Erslev, E.A., 1991. Trishear fault-propagation folding. Geology 19, 617-620.

Finch, E., Hardy, S., Gawthorpe, R., 2003. Discrete element modeling of contractional fault-propagation folding above rigid basement fault blocks. Journal of Structural Geology 25, 515-528.

Hibbitt, Karlsson, Sorensen, Inc, 2004. ABAQUS/CAE User's Manual, Version 6.4-3.

Hitchcock, C.S., Lindvall, S.C., Treiman, J.A., Weaver, K.D., Helms, J.G., Lettis, R.W., 2001. Paleoseismic investigation of the Simi fault, Ventura County, California. U.S. Geological Survey National Earthquake Hazards Reduction Program Award No. 99-HQ-GR0094, Final Technical Report.

Johnson, K.M., Johnson, A.M., 2002. Mechanical models of trishearlike folds. Journal of Structural Geology 24, 277-287.

Johansson, J., Konagai, K., 2004. Fault surface rupture experiments: a comparison of dry and saturated soils. Proceeding of 27th Symposium on Earthquake Engineering, JSCE, Paper No. 271.

Kelson, K.I., Kang, K.H., Page, W.D., Lee, C.T., Cluff, L.S., 2001. Representative styles of deformation along the Chelungpu Fault from the 1999 Chi-Chi (Taiwan) earthquake: geomorphic characteristics and responses of man-made structures. Bulletin of the Seismological Society of America 91 (5), 930-952.

Konagai, K. (Ed.), 2001. 1st Workshop on Seismic Fault-induced Failures-Possible Remedies for Damage to Urban Facilities, Tokyo, Japan. http://shake.iis.u-tokyo.ac.jp/seismic-fault/.

Konagai, K. (Ed.), 2003. JSCE/ Eq AP Workshop on Seismic Faultinduced Failures-Possible Remedies for Damage to Urban Facilities, Tokyo, Japan. http://shake.iis.u-tokyo.ac.jp/seismic-fault/.

Lade, P.V., Cole, D.A., Cummings, D., 1984. Multiple failure surfaces over dip-slip faults. Journal of Geotechnical Engineering 110, 616-627.

Lazarte, C.A., Bray, J.D., 1996. A study of strike-slip faulting using small-scale models. Journal of Geotechnical Testing 19, 118-129.

Lee, W.J., Hamada, M., 2005. An experimental study on earthquake fault rupture propagation through a sandy soil deposit. Journal of Structure Engineering/Earthquake Engineering, JSCE 22, 1s-13s.
Lee, J.C., Chen, Y.G., Sieh, K., Mueller, K., Chen, W.S., Chu, H.T., Chan, Y.C., Rubin, C., Yeats, R., 2001. A vertical exposure of the 1999 surface rupture of the Chelungpu fault at Wufeng, western Taiwan: structural and paleoseismic implications for an active thrust fault. Bulletin Seismological of America 91 (5), 914-929.

Lee, J.C., Rubin, M.C., Mueller, K., Chen, Y.G., Chan, Y.C., Sieh, K., Chu, H.T., Chen, W.S., 2004. Quantitative analysis of movement along an earthquake thrust scarp: a case study of a vertical exposure of the 1999 surface rupture of the Chelungpu fault at Wufeng, western Taiwan. Journal of Asian Earthquake Science 23, 263-273.

Lin, M.L., Jeng, F.S., Wang, H.J., Wang, C.P., Chung, C.F., Yao, Daniel., Chan, S.J., 2005a. Response of soil and a submerged tunnel during a thrust fault offset based on model experiment and numerical analysis, PVP2005-71179. Proceedings of PVP2005 ASME Pressure Vessels and Piping Division Conference, Denver, Colorado USA.

Lin, M.L., Lu, C.Y., Chang, K.J., Jeng, F.S., Lee, C.J., 2005b. Sandbox experiments of plate convergence-scale effect and associated mechanisms. Terrestrial, Atmospheric and Oceanic Sciences 16 (3), 595-620.

Nino, F., Philip, H., Chery, J., 1998. The role of bed-parallel slip in the formation of blind thrust faults. Journal of Structural Geology 20 (5), 503-516.

Ota, Y., Chen, Y.G., Chen, W.S., 2005. Review of paleoseismological and active fault studies in Taiwan in the light of the Chichi earthquake of September 21, 1999. Tectonophysics 408, 63-77.

Roth, W.H., Sweet, J., Goodman, R.E., 1982. Numerical and physical modeling of flexural slip phenomena and potential for fault movement. Rock Mechanics. Supplementum 12, 27-64.

Roering, J.J., Cooke, M.L., Pollard, D.D., 1997. Why blind thrust faults do not propagate to Earth's surface: numerical modeling of coseismic deformation associated with thrust-related anticlines. Journal of Geophysical Research 102 (B6), 11,901-11,912.

Schultz, R.A., 2000. Localization of bedding-plane slip and backthrust faults above blind thrust faults: key to wrinkle rigid structure. Journal of Geophysical Research 105 (E5), 12035-12052.

Tani, K., Ueta, K., Onizuka, N., 1994. Scale effect of Quaternary ground deformation observed in model tests of vertical fault. Proceeding of 29th Japan National Conference on SMFE, pp. 1359-1362.

Wang, W.L., Wang, T.T., Su, J.J., Lin, C.H., Seng, C.R., 2001. Assessment of damages in mountain tunnels due to the Taiwan ChiChi earthquake. Tunnels \& Undergound Space 16 (3), 133-150.

Zehnder, A.T., Allmendinger, R.W., 2000. Velocity field for the trishear model. Journal of Structural Geology 22, 1009-1014. 